See discussions, stats, and author profiles for this publication at: https://www.researchgate.net/publication/309618222

\title{
Gene expression profile in heat-shocked Holstein and Nelore oocytes and cumulus cells
}

Article in Reproduction Fertility and Development · November 2016

DOI: $10.1071 /$ RD16154

CITATIONS

6

15 authors, including:

Janahi Ticianelli

São Paulo State University

4 PUBLICATIONS 52 CITATIONS

SEE PROFILE

R. A. Satrapa

São Paulo State University

47 PUBLICATIONS 315 CITATIONS

SEE PROFILE
102

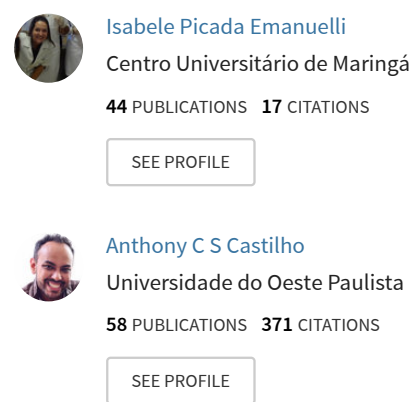

Some of the authors of this publication are also working on these related projects:

Timed Artificial Insemination (TAI) in Zebu cattle View project

EFFECTS OF PREGNANCY-ASSOCIATED PLASMA PROTEIN A (PAPP-A) ON OOCYTE AND EMBRYO COMPETENCE View project 


\title{
Gene expression profile in heat-shocked Holstein and Nelore oocytes and cumulus cells
}

\author{
J.S. Ticianelli ${ }^{\mathrm{A}}$, I. P. Emanuelli ${ }^{\mathrm{A}}$, R. A. Satrapa ${ }^{\mathrm{A}}$, A. C. S. Castilho $^{\mathrm{A}}$, B. Loureiro $^{\mathrm{A}}$, \\ M. J. Sudano ${ }^{\mathrm{B}}$, P. K. Fontes ${ }^{\mathrm{A}}$, R. F. P. Pinto ${ }^{\mathrm{A}}$, E. M. Razza ${ }^{\mathrm{A}}$, R. S. Surjus ${ }^{\mathrm{C}}$, \\ R. Sartori ${ }^{\mathrm{C}}$, M. E. O. A. Assumpção ${ }^{\mathrm{D}}$, J. A. Visintin ${ }^{\mathrm{D}}$, C. M. Barros ${ }^{\mathrm{A}}$ \\ and F. F. Paula-Lopes ${ }^{\mathrm{A}, \mathrm{E}, \mathrm{F}}$ \\ A Department of Pharmacology, Institute of Biosciences, São Paulo State University (UNESP), \\ 18618-970 Botucatu, Brazil. \\ ${ }^{B}$ Department of Animal Reproduction and Veterinary Radiology, School of Veterinary Medicine \\ and Animal Science (FMVZ), São Paulo State University (UNESP), Prof. Dr. Walter Mauricio \\ Correra Street, 18618-970 Botucatu, Brazil. \\ ${ }^{C}$ Department of Animal Sciences, Luiz de Queiroz College of Agriculture (ESALQ), University of \\ São Paulo (USP), Pádua Dias Avenue 11, 13418-900 Piracicaba, Brazil. \\ D Department of Animal Reproduction, School of Veterinary Medicine and Animal Science \\ (FMVZ), University of São Paulo (USP), Orlando Marques de Paiva Street, 87, \\ 05508-270 São Paulo, Brazil.

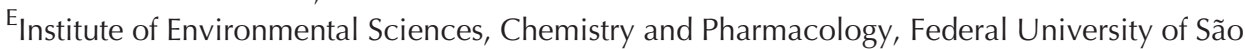 \\ Paulo (UNIFESP), Prof. Artur Riedel Street 275, 09913-030 Diadema, Brazil. \\ FCorresponding author. Email: paula.lopes29@unifesp.br
}

\begin{abstract}
The present study determined the transcriptome profile in Nelore and Holstein oocytes subjected to heat shock during IVM and the mRNA abundance of selected candidate genes in Nelore and Holstein heat-shocked oocytes and cumulus cells (CC). Holstein and Nelore cows were subjected to in vivo follicle aspiration. Cumulus-oocyte complexes were assigned to control $\left(38.5^{\circ} \mathrm{C}, 22 \mathrm{~h}\right)$ or heat shock $\left(41^{\circ} \mathrm{C}\right.$ for $12 \mathrm{~h}$, followed by $38.5^{\circ} \mathrm{C}$ for $\left.10 \mathrm{~h}\right)$ treatment during IVM. Denuded oocytes were subjected to bovine microarray analysis. Transcriptome analysis demonstrated 127 , nine and six genes were differentially expressed between breed, temperature and the breed $\times$ temperature interaction respectively. Selected differentially expressed genes were evaluated by real-time polymerase chain reaction in oocytes and respective CC. The molecular motor kinesin family member $3 \mathrm{~A}(K I F 3 A)$ was upregulated in Holstein oocytes, whereas the pro-apoptotic gene death-associated protein $(D A P)$ and the membrane trafficking gene DENN/MADD domain containing 3 (DENND3) were downregulated in Holstein oocytes. Nelore CC showed increased transcript abundance for tight junction claudin 11 (CLDN11), whereas Holstein CC showed increased transcript abundance for antioxidant metallothionein 1E $(M T 1 E)$. Moreover, heat shock downregulated antioxidant MT1E mRNA expression in CC. In conclusion, oocyte transcriptome analysis indicated a strong difference between breeds involving organisation and cell death. In $\mathrm{CC}$, both breed and temperature affected mRNA abundance, involving cellular organisation and oxidative stress.
\end{abstract}

Additional keywords: Bos taurus indicus, Bos taurus taurus, mRNA, microarray, real-time polymerase chain reaction.

Received 15 April 2016, accepted 20 September 2016, published online 2 November 2016

\section{Introduction}

Genetic divergences have been observed in animal breeds that evolved under different environmental conditions. For example, Bos taurus indicus animals are less sensitive to the deleterious effects of heat stress than Bos taurus taurus (Rocha et al. 1998). High environmental temperatures during the hot months of the year reduce reproductive performance in cattle. Furthermore, the magnitude of the deleterious effects of heat stress on fertility is more pronounced in high-producing dairy cows because the high metabolic heat production associated with lactation can lead to hyperthermia (Al-Katanani et al. 1999). The resistance of B. taurus indicus to heat stress is related to their 
thermoregulatory efficiency (Hansen 2004) and cellular thermotolerance (Paula-Lopes et al. 2003, 2013).

Heat stress promotes a series of physiological and cellular alterations in different tissues compromising follicular growth (Wolfenson et al. 1995), hormonal secretion (Roth et al. 2000), endometrial function (Malayer et al. 1988), uterine blood flow (Roman-Ponce et al. 1978) and preimplantation embryonic development (Ealy et al. 1993), as well as the function of oocytes (Al-Katanani et al. 2002) and cumulus cells (CCs; Rispoli et al. 2013). It has already been demonstrated that exposure of bovine oocytes to high temperatures reduces fertilisation and oocyte developmental competence (Roth and Hansen 2005).

Heat-induced damage in bovine oocytes causes cytoplasmic changes, such as a reduction in oocyte protein synthesis (Edwards and Hansen 1996), disorganisation of microfilaments and microtubules (Roth and Hansen 2005), changes in cortical granule redistribution (Maya-Soriano et al. 2013) and a reduction in mitochondrial activity (Paula-Lopes et al. 2013). Heat shock also affects nuclear events, reducing oocyte meiotic maturation (Roth and Hansen 2005) and inducing DNA fragmentation (Roth and Hansen 2004). Moreover, high temperature affects oocyte quality at the molecular level. Exposure of germinal vesicle $(\mathrm{GV})$ oocytes to seasonal heat stress increased the abundance of heat shock protein 70 (HSP70) transcript; this heat-induced increase in HSP70 mRNA was greater for Holstein than Gyr oocytes (Camargo et al. 2007). Seasonal heat stress also reduced oocyte relative abundance of transcripts involved in oocyte maturation and preimplantation embryonic development (Gendelman and Roth 2012). However, very little is known regarding the effects of heat stress during oocyte maturation on gene expression.

The bovine oocyte is surrounded by layers of CCs. Bidirectional communication between the oocyte and its CCs plays an important role in oocyte growth, metabolism (Haghighat and Van Winkle 1990) and maturation (Tanghe et al. 2002). Removal of CCs before IVM is detrimental to oocyte maturation in cattle (Chian and Sirard 1995). Similarly, a reduction in CC function may affect both the oocyte and CCs. Exposure of cumulus-oocyte complexes (COCs) to heat shock during IVM induced CC DNA fragmentation (Nabenishi et al. 2012) and altered the transcriptome profile in CCs (Rispoli et al. 2013).

Bovine preimplantation embryonic development is dependent on mRNA stored during oocyte growth (Trounson et al. 2001). Translational control pathways, such as translation activation through polyadenylation, transcript silencing and degradation through desadenylation, ensure mRNA storage required for oocyte competence and subsequent preimplantation embryonic development (Decker and Parker 1994; Brevini-Gandolfi and Gandolfi 2001). The bovine oocyte is transcriptionally quiescent during maturation. Indeed, oocyte transcriptional activity has been shown to be high until the oocyte reaches $110 \mu \mathrm{m}$ (2- to $3-\mathrm{mm}$ diameter follicle), decreases up to the GV stage and decreases markedly as the oocyte reaches the MII stage (Brevini-Gandolfi and Gandolfi 2001). For example, the amount of poly(A) RNA was reported to be highest in GV oocytes and to drop after $12 \mathrm{~h} \mathrm{IVM} \mathrm{(Payton}$ et al. 2011). Interestingly, exposure of bovine oocytes to
$41{ }^{\circ} \mathrm{C}$ heat shock during the first $12 \mathrm{~h}$ of IVM did not affect oocyte total RNA, RNA size distribution or poly(A) RNA (Payton et al. 2011). Hence the molecular mechanisms triggered by elevated temperature in bovine oocytes during maturation remain unknown, as do the determinant factors related to thermotolerance between $B$. taurus taurus and B. taurus indicus.

Thus, the aim of the present study was to evaluate the hypothesis that differences in thermotolerance between $B$. taurus indicus and B. taurus taurus oocytes are due to differential gene expression. Therefore, the global gene expression profile was determined in Nelore and Holstein oocytes subjected to heat shock during IVM. In addition, candidate genes selected from oocyte microarray were evaluated by realtime polymerase chain reaction (PCR) in Nelore and Holstein oocytes and their surrounding CCs. Even though the gene expression profile between oocytes and CCs can differ, the present study also evaluated how genes differentially expressed on oocyte microarray behave in CCs subjected to the same treatments.

\section{Materials and methods}

Unless stated otherwise, all reagents and media were purchased from Sigma-Aldrich. Animals were managed according to the School of Veterinary Medicine and Animal Sciences Bioethical Committee from University of São Paulo (São Paulo, Brazil).

\section{Experimental design}

The experiment was designed as a $2 \times 2$ factorial to evaluate the effects of breed (Holstein and Nelore) and temperature $\left(38.5^{\circ} \mathrm{C}\right.$ and $41^{\circ} \mathrm{C}$ ) on differential gene expression in bovine oocytes (microarray and real-time PCR) and CCs (real-time PCR). Therefore, Holstein and Nelore COCs were randomly assigned to in vitro heat shock $\left(41^{\circ} \mathrm{C}\right.$ for $12 \mathrm{~h}$, followed by $38.5^{\circ} \mathrm{C}$ for $10 \mathrm{~h})$ and control $\left(38.5^{\circ} \mathrm{C}, 22 \mathrm{~h}\right)$ treatments during IVM.

\section{Animals}

Non-lactating Holstein $(n=13)$ and Nelore $(n=14)$ cows were housed together at the central-east region of Sao Paulo State, Brazil $\left(22^{\circ} 42^{\prime} 30^{\prime \prime} \mathrm{S}, 47^{\circ} 38^{\prime} 30^{\prime \prime} \mathrm{W} ; 546 \mathrm{~m}\right.$ above sea level) and maintained under the same management conditions, including maintenance diet. Animals were $4-8$ years of age, with a mean ( \pm s.e.m.) body condition score (on a scale of $1-5$ ) of $3.1 \pm 0.1$ for Nelore and $2.8 \pm 0.2$ for Holstein and mean $( \pm$ s.e.m. $)$ weight of $508 \pm 17 \mathrm{~kg}$ for Nelore and $575 \pm 20 \mathrm{~kg}$ for Holstein.

One week before follicular aspiration, a data logger was installed in the free stall to monitor environmental temperature $\left(\mathrm{ET} ;{ }^{\circ} \mathrm{C}\right)$ and relative air humidity $(\mathrm{RH} ; \%)$ each hour of the day during the entire experiment. Average ET and RH were determined to calculate the temperature and humidity index (THI) (Kelly and Bond 1971) in order to characterise environmental conditions. According to Armstrong (1994), THI <72 indicates the absence of heat stress, THI 72-78 indicates mild heat stress, THI 79-88 indicates moderate heat stress and THI 89-98 indicates severe heat stress. Rectal temperature (RT; $\left.{ }^{\circ} \mathrm{C}\right)$ and respiratory rate (RR; movements per minute (m.p.m.)) of each animal were also determined during follicular aspiration. 


\section{Oocyte collection}

Ovum pick-up (OPU; $n=12$ ) was performed during the winter and spring seasons (July-November). The device used was an Aloka SSD-500 ultrasound with a sector transducer of $5 \mathrm{MHz}$ adapted to an $18-\mathrm{G}$ needle connected to a sterile test tube and a vacuum line $(85 \mathrm{mmHg})$. Recovered COCs were transferred to $50-\mathrm{mL}$ conical tubes containing $10 \mathrm{~mL}$ phosphate-buffered saline (PBS) supplemented with $5 \mathrm{IU} \mathrm{mL}^{-1}$ heparin. COCs were transferred to $80 \mu \mathrm{L}$ washing medium (TCM 199-HEPES supplemented with $10 \%(\mathrm{v} / \mathrm{v})$ fetal bovine serum (FBS; GIBCO BRL), $2 \mu \mathrm{g} \mathrm{mL}^{-1}$ pyruvate and $78 \mu \mathrm{g} \mathrm{mL}^{-1}$ amikacin sulfate) and stored in cryotubes containing $400 \mu \mathrm{L}$ transport medium (TCM 199-HEPES supplemented with $10 \%$ (v/v) FBS, $22 \mu \mathrm{g} \mathrm{mL}^{-1}$ pyruvate, $78 \mu \mathrm{g} \mathrm{mL}^{-1}$ amikacin sulfate, $1 \mu \mathrm{g} \mathrm{mL}^{-1}$ FSH (Folltropin; Bioniche) and $10 \mathrm{IU} \mathrm{mL}^{-1} \mathrm{LH}$ (Lutropin-V; Bioniche)) under mineral oil. The cryotubes were transported to the laboratory at $38.5^{\circ} \mathrm{C}$ in a portable incubator.

\section{IVM}

Oocytes classified as Grade I, II and III containing one or more layers of compact CCs and homogeneous cytoplasm were used in the experiment (Leibfried and First 1979). COCs were transferred to $50-\mu \mathrm{L}$ microdrops of IVM medium (TCM 199bicarbonate containing $10 \%(\mathrm{v} / \mathrm{v}) \mathrm{FBS}, 22 \mu \mathrm{g} \mathrm{mL}^{-1}$ pyruvate, $75 \mu \mathrm{g} \mathrm{mL}^{-1}$ gentamycin, $1 \mu \mathrm{g} \mathrm{mL}^{-1} \mathrm{FSH}$ and $\left.10 \mathrm{IU} \mathrm{mL}^{-1} \mathrm{LH}\right)$ under mineral oil. At each OPU $(n=12)$, Holstein and Nelore COCs were randomly distributed into control $\left(38.5^{\circ} \mathrm{C}, 22 \mathrm{~h}\right)$ and heat shock $\left(41^{\circ} \mathrm{C}\right.$ for $12 \mathrm{~h}$, followed by $38.5^{\circ} \mathrm{C}$ for $\left.10 \mathrm{~h}\right)$ treatment groups during IVM under an atmosphere of $5 \%$ of $\mathrm{CO}_{2}$ in humidified air. The total number of COCs collected for each treatment was as follows: Nelore control, 302 COCs; Nelore heat shock, 316 COCs; Holstein control, 102 COCs; and Holstein heat shock, 106 COCs. A separate group of Nelore slaughterhouse-derived COCs was matured in vitro, fertilised and cultured. These COCs were used as an IVF laboratory control. The percentage of oocytes that cleaved at Day 2 and reached the blastocyst stage at Day 7 after insemination was $84.5 \pm 2.3 \%$ and $39.5 \pm 2.5 \%$ respectively. Both IVF and values of cleaved and reached blastocyst were obtained by Silva et al. (2013).

\section{Removal and storage of CCs}

After maturation, COCs were initially denuded by repeated pipetting in $100-\mu \mathrm{L}$ drops of $\mathrm{Ca}^{2+}$ - and $\mathrm{Mg}^{2+}$-free PBS. Oocytes were removed from the drop and CCs $(n=5$ pools in $100 \mu \mathrm{L}$ per experimental group) were stored at $-80^{\circ} \mathrm{C}$ until real-time PCR analysis. Partially denuded oocytes were transferred to $50-\mu \mathrm{L}$ microdrops containing $10000 \mathrm{IU} \mathrm{mL}^{-1}$ hyaluronidase at $38^{\circ} \mathrm{C}$ for 3-7 min, followed by incubation in $50-\mu \mathrm{L}$ microdrops containing $5 \mathrm{mg} \mathrm{mL}^{-1}$ protease for $5-10 \mathrm{~s}$. Denuded oocytes were washed in $50-\mu \mathrm{L}$ microdrops of $\mathrm{Ca}^{2+}$ - and $\mathrm{Mg}^{2+}$-free PBS containing 5\% (v/v) FBS for protease inactivation and washed three times in $50-\mu \mathrm{L}$ microdrops of $\mathrm{Ca}^{2+}$ - and $\mathrm{Mg}^{2+}$-free PBS. Oocytes ( $n=3$ replicates of 25 putative MII oocytes per experimental group) were stored at $-80^{\circ} \mathrm{C}$ until microarray and real-time PCR analysis.

\section{RNA extraction, amplification and concentration}

Total RNA was extracted from oocytes using the RNeasy Mini Kit (Qiagen) as recommended by the manufacturer. Total RNA quality and yield were determined using a Bioanalyser 2100 (Agilent Technologies) with an RNA 6000 Pico LabChip Kit (Agilent Technologies) and spectrophotometer (NanoDrop ND2000 UV-Vis Spectrophotometer; NanoDrop Technologies). To obtain 100 ng RNA from oocyte pools, samples were amplified using a MessageAmp II aRNA Amplification Kit (Ambion) according to the manufacturer's instructions. Briefly, samples were subjected to the reverse transcription process, doublestranded cDNA synthesis and in vitro transcription for amplified RNA (aRNA) synthesis. Samples that did not reach the desired concentration were further concentrated (Concentrator 5301; Eppendorf) for short intervals of 5 and $10 \mathrm{~min}$ over a period of $40 \mathrm{~min}$, at room temperature. aRNA was quantified in a NanoDrop spectrophotometer and stored at $-80^{\circ} \mathrm{C}$.

Total RNA was extracted from CCs using an RNeasy Micro Kit (Qiagen) according to the manufacturer's instructions. Extracted RNA was quantified in a NanoDrop spectrophotometer and stored at $-80^{\circ} \mathrm{C}$.

\section{Oocyte microarray analysis}

Total RNA samples (100 ng) were subjected to reverse transcription reaction for cDNA formation. cDNA was used as template for the in vitro transcription reaction resulting in biotinlabelled aRNA. Then, aRNA was fragmented using a $3^{\prime}$ IVT Express Kit (Affymetrix) and subjected to hybridisation using a GeneChip Bovine Array (Affymetrix) according to the manufacturer's instructions. GeneChips were scanned using a GeneChip scanner (Model 3000 7G; Affymetrix). In all, 75 oocytes per treatment $(n=3$ replicates of 25 putative MII oocytes per experimental group) were subjected to microarray analysis. DAVID Bioinformatics Database software (www. david.abcc.ncifcrf.gov, accessed 15 February 2013; Huang et al. 2009) and Ingenuity pathways analysis (IPA; Ingenuity Systems; www.ingenuity.com, accessed 15 February 2013) were used to identify functions and relationships that were most significant between genes.

\section{Oocyte microarray validation by real-time PCR}

Following microarray, genes associated with cellular changes triggered by heat shock were selected for validation by real-time PCR (Table 1). Primers for kinesin family member 3A (KIF3A), claudin 11 (CLDN11), baculoviral IAP repeat-containing 3 $(B I R C 3)$, death-associated protein $(D A P)$, metallothionein $1 \mathrm{E}$ (MT1E), chaperonin containing TCP1, subunit 4 (CCT4), acyl-coenzyme A oxidase 1, palmitoyl (ACOXI), dicer 1, ribonuclease type III (DICER1) and DENN/MADD domain containing 3 (DENND3) were designed from sequences available in the GenBank database. Selected primers were synthesised by Integrated DNA Technologies (IDT) Inc. Nucleotide sequences and the annealing temperature of selected forward and reverse primers are presented in Table 2. Oocyte RNA samples were pretreated with DNAse I (amplification grade; Invitrogen) before real-time PCR in order to avoid contamination with genomic DNA. aRNA (100 ng per sample) from 
Table 1. Selected genes for validation by real time-polymerase chain reaction

\begin{tabular}{|c|c|c|c|c|}
\hline Representative public ID & Gene name & Gene symbol & Fold-change & $P$-value \\
\hline \multicolumn{5}{|l|}{ Breed } \\
\hline \multicolumn{5}{|c|}{ Upregulated in Holstein oocytes } \\
\hline CB167318 & Kinesin family member 3 & KIF3A & 10.83 & 0.0032 \\
\hline CB442788 & Claudin 11 & CLDN11 & 4.01 & 0.0286 \\
\hline CB448293 & Baculoviral IAP repeat-containing 3 & $B I R C 3$ & 3.65 & 0.0037 \\
\hline \multicolumn{5}{|c|}{ Downregulated in Holstein oocytes } \\
\hline CK975976 & Death-associated protein & $D A P$ & 1.53 & 0.0382 \\
\hline \multicolumn{5}{|c|}{ Temperature } \\
\hline \multicolumn{5}{|c|}{ Downregulated in heat-shocked oocytes } \\
\hline BE685559 & Metallothionein 1E & MTIE & -1.52 & 0.0436 \\
\hline \multicolumn{5}{|c|}{ Breed $\times$ temperature interaction } \\
\hline CK946415 & Acyl-CoA oxidase 1, palmitoyl & $A C O X 1$ & -1.58 & 0.0359 \\
\hline CB451598 & Chaperonin containing TCP1, subunit 4 & CCT4 & -1.61 & 0.0259 \\
\hline CB446568 & DENN/MADD domain containing 3 & DENND3 & -1.68 & 0.0318 \\
\hline NM_203359.1 & Dicer 1, ribonuclease type III & DICERI & -1.77 & 0.0400 \\
\hline
\end{tabular}

Table 2. Primers sequences and amplicon size used for real time-polymerase chain reaction $K I F 3 A$, kinesin family member $3 \mathrm{~A} ; C L D N 11$, claudin $11 ; B I R C 3$, baculoviral IAP repeat-containing 3; DAP, death-associated protein; $M T 1 E$, metallothionein $1 \mathrm{E} ; A C O X 1$, acyl-coenzyme A oxidase 1, palmitoyl; CCT4, chaperonin containing TCP1, subunit 4; DENND3, DENN/MADD domain containing 3; DICER1, dicer 1, ribonuclease type III; $A C T B, \beta$-actin; $R P L 15$, ribosomal protein L15; RPL30, ribosomal protein L30; GAPDH, glyceraldehyde 3-phosphate dehydrogenase; PPIA, peptidylprolyl isomerase A

\begin{tabular}{|c|c|c|c|}
\hline Gene & Primer sequence & Size (bp) & Annealing temperature $\left({ }^{\circ} \mathrm{C}\right)$ \\
\hline$K I F 3 A$ & $\begin{array}{l}\text { Forward: 5'-GCAGACTCCAGTTCCAGATAAA-3' } \\
\text { Reverse: 5'-CGAAGGCTTTCCTCAGTATAGG-3' }\end{array}$ & 90 & 60 \\
\hline CLDN11 & $\begin{array}{l}\text { Forward: 5'-TCTCAGCTCCAAGGTCACTTA-3' } \\
\text { Reverse: } 5^{\prime} \text {-CCTCACCTTACAAGAGGGAAA- } 3^{\prime}\end{array}$ & 126 & 60 \\
\hline BIRC3 & $\begin{array}{l}\text { Forward: 5'-GACTGAGGTGTTGGGAATCTG-3' } \\
\text { Reverse: } 5^{\prime} \text {-ACTGGCTTGAACTCGACTAATG-3' }\end{array}$ & 119 & 60 \\
\hline$D A P$ & $\begin{array}{l}\text { Forward: 5'-CACCAGAGAAGAGAAGGACAAG-3' } \\
\text { Reverse: 5'-CGATGACTCCGGAGATAAACAC-3' }\end{array}$ & 86 & 60 \\
\hline$M T 1 E$ & $\begin{array}{l}\text { Forward: 5'-CTCTACTTTGCCACTTGCTTTG-3' } \\
\text { Reverse: } 5^{\prime} \text {-CTTCTTGCAGGAGGGACATC-3' }\end{array}$ & 137 & 60 \\
\hline$A C O X 1$ & $\begin{array}{l}\text { Forward: 5'-GACTCGAGATAATTGGCACCTAC-3' } \\
\text { Reverse: } 5^{\prime} \text {-CCTGGGTTTCAGGGTCATAAG-3' }\end{array}$ & 99 & 60 \\
\hline CCT4 & $\begin{array}{l}\text { Forward 5'-GCTGAGGAGGTCAGCTTAAAT-3' } \\
\text { Reverse: 5'-CACAGAGAGCATCATGGATAGAG-3' }\end{array}$ & 148 & 60 \\
\hline DENND3 & $\begin{array}{l}\text { Forward: 5'-GTGGGAACATCACCTACTCTAAC-3' } \\
\text { Reverse: } 5^{\prime} \text {-CTC TGG ACC CTC TGA ATG AAC-3' }\end{array}$ & 91 & 60 \\
\hline DICERI & $\begin{array}{l}\text { Forward: 5'-CGTTTACTCATCTGGCTCCTAAA-3' } \\
\text { Reverse: 5'-CAACAATGGAGGCTCGAAGA-3' }\end{array}$ & 108 & 60 \\
\hline$A C T B$ & $\begin{array}{l}\text { Forward: } 5^{\prime} \text {-GCGTGGCTACAGCTTCACC- } 3^{\prime} \\
\text { Reverse: } 5^{\prime} \text {-TTGATGTCACGGACGATTTC- } 3^{\prime}\end{array}$ & 55 & 60 \\
\hline RPL15 & $\begin{array}{l}\text { Forward: 5'-CTCATCGTTGGTGCCAATGCAAGT-3' } \\
\text { Reverse: } 5^{\prime} \text {-TCACATCCACCCTGGGAAACAGAA-3' }\end{array}$ & 192 & 60 \\
\hline RPL30 & $\begin{array}{l}\text { Forward: 5'-TGGTGTCCATCACTACAGTGGCAA-3' } \\
\text { Reverse: 5'-ACCAGTCTGTTCTGGCATGCTTCT-3' }\end{array}$ & 133 & 60 \\
\hline$G A P D H$ & $\begin{array}{l}\text { Forward: 5'-GGCGTGAACCACGAGAAGTATAA-3' } \\
\text { Reverse: 5'-CCCTCCACGATGCCAAAG-3' }\end{array}$ & 119 & 60 \\
\hline PPIA & $\begin{array}{l}\text { Forward: 5'-GCCATGGAGCGTTTTGG-3' } \\
\text { Reverse: } 5^{\prime} \text {-CCACAGTCAGCAATGGTGATCT-3' }\end{array}$ & 65 & 60 \\
\hline
\end{tabular}


oocyte samples subjected to microarray was reverse transcribed using Oligo-dT primer and SuperScript III (Invitrogen). Expression of target genes was investigated using a Power SybrGreen detection system (Applied Biosystems) and a Step One Plus Real-Time PCR System (Applied Biosystems). Initial real-time PCR analysis investigated genes affected by temperature, breed and the breed $\times$ temperature interaction using 75 oocytes per treatment $(n=3$ replicates of 25 putative MII oocytes per experimental group). The RefFinder program (http://www.leonxie.com, accessed 7 October 2013) was used to determine the best reference gene for oocytes. For these samples $\beta$-actin $(A C T B)$ was chosen as the most appropriate reference gene rather than the ribosomal protein L15 (RPL15), ribosomal protein L30 (RPL30) and glyceraldehyde 3-phosphate dehydrogenase $(G A P D H)$ genes.

\section{$C C$ real-time $P C R$}

CC real-time PCR was conducted for the same genes and primers described above for oocyte real-time PCR (Table 2). CC RNA samples were pretreated with DNAse I (amplification grade; Invitrogen) before real-time PCR. CC total RNA (100 ng per sample) was reverse transcribed using Oligo-dT primer and SuperScript III (Invitrogen). Expression of target genes was investigated using a Power SybrGreen detection system (Applied Biosystems) and Step One Plus Real-Time PCR System (Applied Biosystems). The RefFinder program was used to determine the best reference gene for CCs. For these samples, $R P L 30$ was chosen as the most appropriate reference gene rather than RPL15, ACTB and peptidylprolyl isomerase A (PPIA).

\section{Statistical analysis}

Environmental temperature, RH, THI, RR and RT were analysed by least-squares analysis of variance (ANOVA) using the general linear model (GLM) procedure of SAS (SAS for Windows, version 9.0; SAS Institute). The significance of differences between individual means was further analysed by complete pair-wise comparisons (probability of difference analysis; SAS Institute).

Microarray data were analysed using FlexArray 1.6.1.1 (Blazejczyk et al. 2007). Data were subjected to a simple background correction, normalised within and between each array and analysed statistically through the use of linear models for microarray data analysis (LIMMA; Smyth 2005). Further analyses were performed using the affy program package developed in the $\mathrm{R}$ language (Gautier et al. 2004). Probeset intensity row data for each probe was determined, followed by background subtraction, normalisation between arrays and mean probeset intensity from each transcript representing its final intensity. Genes with fold-changes of at least 1.5 and $P<0.05$ were considered differentially expressed in both analyses.

Pearson's correlation was calculated between oocyte microarray and real-time PCR fold-changes using GraphPad Prism 6 (GraphPad Software). For oocyte and CC real-time PCR analysis, the relative expression of each target gene was calculated using the ${ }^{\Delta \Delta} \mathrm{C}_{\mathrm{T}}$ method. Amplification efficiency correction was determined using the equation described by Pfaffl (2001). Average efficiency values for each gene were calculated using
LinRegPCR software (Ramakers et al. 2003). Oocyte data were subjected to ANOVA using JMP version 7.0 (SAS Institute), whereas CC data were subjected to ANOVA using the GLM procedure of SAS for Windows, version 9.0 (SAS Institute). Logarithmic or square root transformation was used to obtain a normal distribution whenever necessary. The model included the main effects of breed and temperature and the breed $x$ temperature interaction.

\section{Results}

\section{Environmental parameters}

ET and RH were measured every hour during the OPU period to determine animal comfort (Fig. 1). ET varied from a maximum of $28.05 \pm 0.29^{\circ} \mathrm{C}$ to a minimum of $16.88 \pm 0.29^{\circ} \mathrm{C}$. ET was lower in the morning than in the evening $(19.21 \pm 0.73$ vs $25.00 \pm 0.73^{\circ} \mathrm{C}$ respectively; $\left.P<0.0001\right)$. $\mathrm{RH}$ varied from a maximum of $77.36 \pm 1.30 \%$ to a minimum of $44.79 \pm 1.30 \%$ and was lower in the evening than in the morning $(52.77 \pm 2.10 \%$ vs $71.09 \pm 2.10 \%$ respectively; $P<0.0001)$.

Critical temperatures for $B$. taurus taurus and B. taurus indicus are $27^{\circ} \mathrm{C}$ and $35^{\circ} \mathrm{C}$ respectively (Curtis 1981). Thus, hyperthermia in $B$. taurus taurus cows can occur at temperatures above $27^{\circ} \mathrm{C}$ (Berman et al. 1985). Despite the fact that in the present study maximum air temperature was borderline, there was an inverse relationship between ET and RH promoting evaporative heat loss, thermoregulation and maintenance of normothermia.

The THI ranged from $58.43 \pm 0.72$ to $76.11 \pm 0.72$ with a mean of $68.06 \pm 0.40$ across the days of the study (OPU). According to Armstrong (1994), these THI values indicate that the animals were not subjected to heat stress for most of the study. Mild environmental stress was observed on 13 random days in September (Fig. 2). It has been reported that THI $>72$ is indicative of mild stress for lactating $B$. taurus taurus cows (Armstrong 1994). Females used in the present study were not lactating, which reduces endogenous heat production, leading to thermal comfort (Sartori et al. 2004).

\section{Physiological parameters}

RT and RR differed between breeds. RT was higher for Nelore than Holstein cows $\left(38.37 \pm 0.04^{\circ} \mathrm{C}\right.$ vs $38.23 \pm 0.05^{\circ} \mathrm{C}$

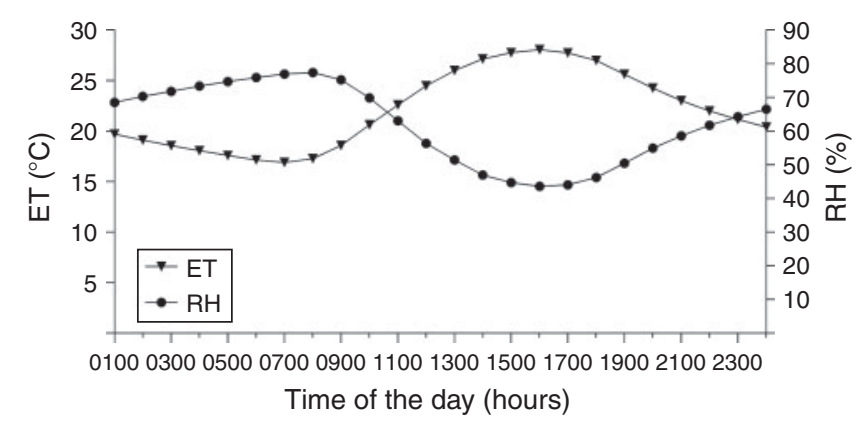

Fig. 1. Hourly environmental temperature (ET) and relative humidity $(\mathrm{RH})$ readings in free stalls during the ovum pick-up period. Data are the least-squares mean \pm s.e.m. 


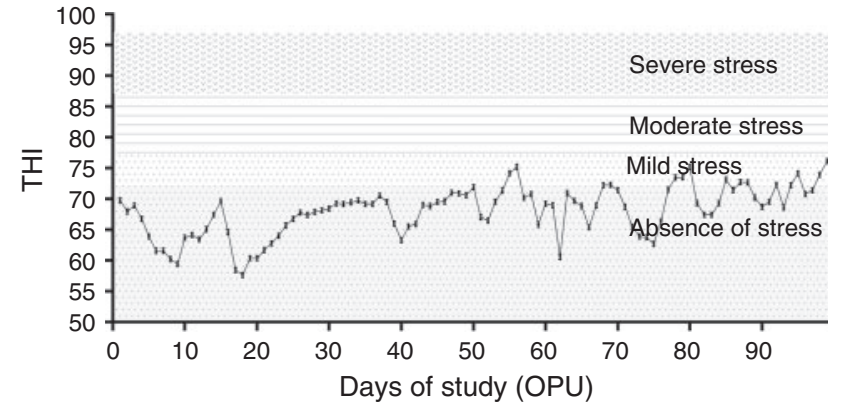

Fig. 2. Characterisation of animal comfort and heat stress according to the temperature and humidity index (THI), calculated using environmental temperature and relative humidity values, during the experimental period. Data are the least-squares mean \pm s.e.m. OPU, ovum pick-up.
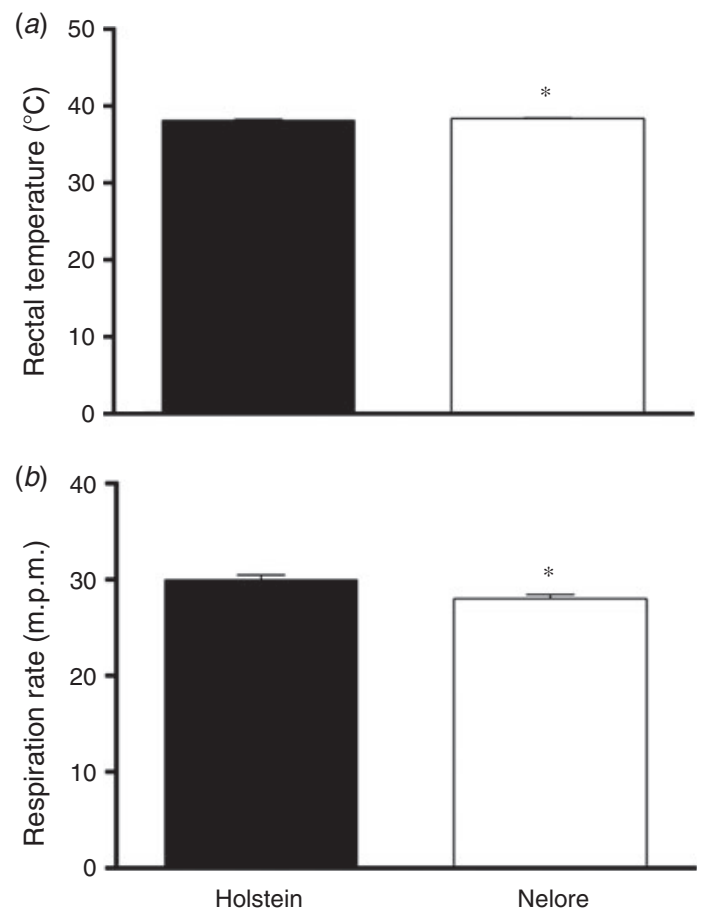

Fig. 3. (a) Rectal temperature and (b) respiration rate in Holstein and Nelore animals measured during ovum pick-up. Data are the least-squares mean \pm s.e.m. $* P<0.05$ compared with Holstein animals. m.p.m., movements per minute.

respectively; $P<0.05$; Fig. $3 a$ ), but RR was higher for Holstein than Nelore cows $(29.99 \pm 0.9$ vs $28.05 \pm 0.44$ m.p.m. respectively; $P<0.05$; Fig. $3 b$ ). The RR and RT of the animals were typical of thermoneutrality (Rhoads et al. 2009).

\section{Transcriptome analysis}

The Venn diagram in Fig. 4 illustrates global gene expression profile in Holstein and Nelore oocytes subjected to heat shock. Oocyte microarray revealed 127 genes affected by breed (Table 3), nine genes affected by temperature (Table 4) and six genes affected by the breed $\times$ temperature interaction (Table 5 ;

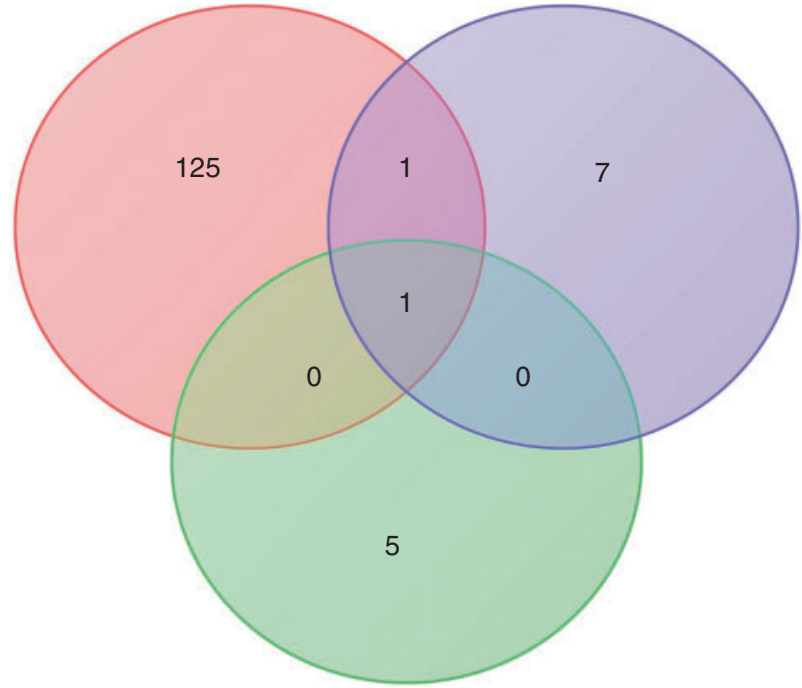

Fig. 4. Venn diagram illustrating the number of differentially expressed genes affected by breed (red; $n=127$ genes), temperature (blue; $n=9$ genes) and the breed $\times$ temperature interaction (green; $n=6$ genes). Intersecting areas indicate common genes.

fold-change $\geq 1.5 ; P<0.05)$. Among these genes, 82 were upregulated and 45 were downregulated in Holstein compared with Nelore oocytes (Table 3). Moreover, three genes were upregulated and six were downregulated in heat-shocked oocytes compared with control (Table 4). The CCT4 gene was upregulated in heat-shocked compared with control Holstein oocytes, the DICERI gene was upregulated in Holstein heatshocked compared with Nelore heat-shocked oocytes and the ACOX1 gene was upregulated in Holstein heat-shocked compared with both Holstein control and Nelore heat-shocked oocytes (Table 6). The oncostatin M receptor (OSMR) gene was upregulated in Nelore heat-shocked compared with Holstein heat-shocked oocytes, whereas DENND3 was upregulated in Nelore control compared with Holstein control oocytes (Table 6).

\section{Functional classification}

Functional analysis was performed using ingenuity pathways analysis (IPA; Ingenuity Systems; www.ingenuity.com, accessed 15 February 2013) and DAVID Bioinformatics Database software (www.david.abcc.ncifcrf.gov, accessed 15 February 2013). Genes that were differently expressed $(P<0.05)$ between Holstein and Nelore oocytes were involved in important biological functions, such as tissue morphology (CLDN11, claudin $23(C L D N 23)$ and ATPase $\mathrm{Ca}++$ transporting type 2C member 1 ( $A T P 2 C 1$ ), embryonic development (KIF3A and Bos taurus A kinase (PRKA) anchor protein 12 (AKAP12), organism development (ectonucleotidepyrophosphatase/phosphodiesterase 2 (ENPP2) and excision repair cross-complementing rodent repair deficiency, complementation group 6 (ERCC6), tissue development (sirtuin 1 (SIRT1) and inosine triphosphatase (ITPA), cellular development (DICERI and PPIA) and cell death and survival (BIRC3 and DAP; Fig. 5). The differently expressed $(P<0.05)$ genes between control and heat-shocked 
Table 3. Differentially expressed genes in Holstein and Nelore oocytes (breed effect)

GPCR, G-protein-coupled receptor; ETBR-LP-1, endothelin B receptor-like protein 1; PAELR, Parkin-associated endothelin receptor-like receptor; AHA1, Activator of Heat Shock 90kDa Protein ATPase Homolog 1; IAP, Inhibitors of apoptosis proteins; HAUS, subunit human Augmin; Vpr, Viral Protein R; UPF3, Up-Frameshift Suppressor 3; LSM1, like Sm 1; PHD, plant homeodomain; ZMYM6, Zinc Finger MYM-Type Containing 6; CD3, cluster of designation 3; SCO, synthesis of cytochrome c oxidase; GPCR, G protein-coupled receptors; ArfGAP2, ADP Ribosylation Factor GTPase Activating Protein 2

\begin{tabular}{|c|c|c|c|c|}
\hline $\begin{array}{l}\text { Representative } \\
\text { public ID }\end{array}$ & Gene name & Gene symbol & $\begin{array}{l}\text { Fold- } \\
\text { change }\end{array}$ & $P$-value \\
\hline \multicolumn{5}{|c|}{ Upregulated in Holstein oocytes } \\
\hline CB167318 & Kinesin family member $3 \mathrm{~A}$ & KIF3A & 10.83 & 0.0032 \\
\hline AV606331 & Cynaptotagmin IV & SYT4 & 5.47 & 0.0404 \\
\hline CK972321 & 4102775 BARC 9BOV Bos taurus cDNA clone 9BOV24_C22 3', mRNA sequence & - & 5.43 & 0.0334 \\
\hline CK776415 & AHA1 activator of heat shock $90 \mathrm{kDa}$ protein ATPase homologue 1 (yeast) & AHSAl & 5.29 & 0.0185 \\
\hline AW325978 & - & - & 5.28 & 0.0018 \\
\hline BE749242 & $\begin{array}{l}\text { C0009505I05.Q1 KM13R KN510 Bos taurus cDNA clone C0009505I05 3', mRNA } \\
\text { sequence }\end{array}$ & - & 4.75 & 0.0105 \\
\hline CB455872 & 713054 MARC 6BOV Bos taurus cDNA 3', mRNA sequence & - & 4.21 & 0.0344 \\
\hline CB442788 & Claudin 11 & CLDN11 & 4.01 & 0.0286 \\
\hline CK772462 & Mitochondrial ribosomal protein L39 & MRPL39 & 3.81 & 0.0278 \\
\hline BE750213 & Claudin 23 & $C L D N 23$ & 3.67 & 0.0086 \\
\hline CB448293 & Baculoviral IAP repeat-containing 3 & $B I R C 3$ & 3.65 & 0.0037 \\
\hline BP106440 & Roundabout axon guidance receptor homologue 1 (Drosophila) & $\mathrm{ROBOI}$ & 3.41 & 0.0215 \\
\hline BF775460 & Arginyltransferase 1 & ATE1 & 3.27 & 0.0247 \\
\hline CB453664 & Zinc finger protein 398 & ZNF398 & 3.27 & 0.0426 \\
\hline CK846085 & $\begin{array}{l}\text { Sirtuin (silent mating type information regulation } 2 \text { homologue) } 1 \text { (Saccharomyces } \\
\text { cerevisiae) }\end{array}$ & SIRT1 & 3.26 & 0.0271 \\
\hline CK972862 & Bos taurus HAUS augmin-like complex subunit 8 & HAUS8 & 3.12 & 0.0443 \\
\hline BI848481 & Male-specific lethal 3 homologue (Drosophila) & MSL3 & 3.09 & 0.0378 \\
\hline CK847223 & Vpr (HIV-1) binding protein & $V P R B P$ & 3.05 & 0.0331 \\
\hline CK968849 & RAD17 homologue (Schizosaccharomyces pombe) & RAD17 & 3.02 & 0.0294 \\
\hline BM251601 & F-box and leucine-rich repeat protein 3 & $F B X L 3$ & 2.99 & 0.0319 \\
\hline CK848518 & Ankyrin repeat and SOCS box-containing 3 & $A S B 3$ & 2.96 & 0.0092 \\
\hline BI774268 & $\begin{array}{l}\text { Pleckstrin homology domain containing, family A (phosphoinositide binding } \\
\text { specific) member } 2\end{array}$ & PLEKHA2 & 2.95 & 0.0101 \\
\hline CB428813 & Activating transcription factor 1 & ATF1 & 2.82 & 0.0360 \\
\hline CK777897 & v-yes-1 Yamaguchi sarcoma viral oncogene homologue 1 & YES1 & 2.78 & 0.0331 \\
\hline CB537961 & ADP-ribosylation factor-like 1 & ARL1 & 2.78 & 0.0102 \\
\hline CB460407 & Coiled-coil domain containing 112 & CCDC112 & 2.77 & 0.0226 \\
\hline BM107454 & $\begin{array}{l}\text { Similar to RAB18, member RAS oncogene family, RAB18, member RAS } \\
\text { oncogene family }\end{array}$ & $\begin{array}{l}\text { LOC616304 /// } \\
\text { RAB18 }\end{array}$ & 2.56 & 0.0224 \\
\hline CB440290 & - & - & 2.56 & 0.0299 \\
\hline CK777386 & Neural precursor cell expressed, developmentally downregulated 1 & NEDD1 & 2.55 & 0.0163 \\
\hline CK970460 & Kelch-like 2, Mayven (Drosophila) & KLHL2 & 2.50 & 0.0332 \\
\hline BI849511 & Uncharacterised LOC100852378 & LOC100852378 & 2.48 & 0.0363 \\
\hline CK727557 & Bend_0A01-008-d12 Day 8 Uterus bend Bos taurus cDNA 3', mRNA sequence & - & 2.45 & 0.0466 \\
\hline CB445505 & - & - & 2.39 & 0.0450 \\
\hline CB421648 & 594684 MARC 6BOV Bos taurus cDNA 3', mRNA sequence & - & 2.37 & 0.0458 \\
\hline CK964049 & 4078547 BARC 9BOV Bos taurus cDNA clone 9BOV13_B12 5', mRNA sequence & - & 2.27 & 0.0256 \\
\hline CB464732 & Bos taurus GTP binding protein 4 & GTPBP4 & 2.25 & 0.0235 \\
\hline CB451120 & DNA topoisomerase II, $\beta$ isozyme; topoisomerase (DNA) II $\beta 180 \mathrm{kDa}$ & $\begin{array}{l}\text { LOC787143/// } \\
\text { TOP2B }\end{array}$ & 2.21 & 0.375 \\
\hline CB165419 & Transmembrane protein 181 & TMEM181 & 2.18 & 0.0497 \\
\hline CK770689 & 958892 MARC 1BOV Bos taurus cDNA 3', mRNA sequence & - & 2.18 & 0.0101 \\
\hline CK979673 & Uncharacterised LOC100847840 & LOC100847840 & 2.16 & 0.0171 \\
\hline CK967025 & $\begin{array}{l}\text { Excision repair cross-complementing rodent repair deficiency, complementation } \\
\text { group } 6\end{array}$ & ERCC6 & 2.15 & 0.0327 \\
\hline CK846762 & Similar to chromosome $\mathrm{X}$ open reading frame 57 & LOC511907 & 2.15 & 0.0075 \\
\hline CK946910 & Coagulation factor II (thrombin) receptor-like 1 & $F 2 R L 1$ & 2.11 & 0.0430 \\
\hline AW654046 & ATP synthase mitochondrial F1 complex assembly factor 1 & ATPAF1 & 2.10 & 0.0061 \\
\hline AW668954 & Small nuclear ribonucleoprotein 48 kDa (U11/U12) & SNRNP48 & 2.05 & 0.0125 \\
\hline CK946184 & Retinitis pigmentosa 2 (X-linked recessive) & $R P 2$ & 2.04 & 0.0429 \\
\hline
\end{tabular}


Table 3. (Continued)

\begin{tabular}{|c|c|c|c|c|}
\hline $\begin{array}{l}\text { Representative } \\
\text { public ID }\end{array}$ & Gene name & Gene symbol & $\begin{array}{l}\text { Fold- } \\
\text { change }\end{array}$ & $P$-value \\
\hline CK846775 & 969322 MARC 4BOV Bos taurus cDNA 3', mRNA sequence & - & 1.98 & 0.0129 \\
\hline CK776519 & 967837 MARC 4BOV Bos taurus cDNA 3', mRNA sequence & - & 1.96 & 0.0138 \\
\hline BE668935 & UPF3 regulator of nonsense transcripts homologue A (yeast) & $U P F 3 A$ & 1.95 & 0.0037 \\
\hline NM_178320.2 & Peptidylprolyl isomerase A (cyclophilin A) & PPIA & 1.95 & 0.0433 \\
\hline CK959025 & $\begin{array}{l}\text { Heterogeneous nuclear ribonucleoprotein D (AU-rich element RNA binding protein } \\
1,37 \mathrm{kDa})\end{array}$ & $H N R N P D$ & 1.93 & 0.0474 \\
\hline AW336381 & RAB27A, member RAS oncogene family & RAB27A & 1.89 & 0.0360 \\
\hline CB451166 & 705913 MARC 6BOV Bos taurus cDNA 3', mRNA sequence & - & 1.87 & 0.0454 \\
\hline CK950528 & LSM1 homologue, U6 small nuclear RNA associated (S. cerevisiae) & LSM1 & 1.87 & 0.0130 \\
\hline NM_203359.1 & Dicer 1, ribonuclease type III & DICERI & 1.87 & 0.0284 \\
\hline BP101546 & Hypothetical protein LOC613274 & LOC613274 & 1.86 & 0.0223 \\
\hline CB428865 & F-box protein 22 & FBXO22 & 1.86 & 0.0306 \\
\hline BP100422 & $\begin{array}{l}\text { BP100422 ORCS bovine liver cDNA Bos taurus cDNA clone ORCS20428 3', } \\
\text { mRNA sequence }\end{array}$ & - & 1.85 & 0.0295 \\
\hline CB169241 & Fumarylacetoacetate hydrolase domain containing 1 & FAHD1 & 1.83 & 0.0334 \\
\hline CB166510 & splicing factor $3 \mathrm{~b}$, subunit $2.145 \mathrm{kDa}$ & $S F 3 B 2$ & 1.80 & 0.0449 \\
\hline BM363690 & PHD finger protein 11 & PHF11 & 1.74 & 0.0330 \\
\hline CK772848 & Similar to chromosome 17 open reading frame 63 & LOC506074 & 1.74 & 0.0227 \\
\hline CK775501 & Calmodulin-like 4 & CALML4 & 1.74 & 0.0440 \\
\hline CK729309 & Cortactin-binding protein 2 & LOC530341 & 1.71 & 0.0284 \\
\hline BP103418 & $\begin{array}{l}\text { NADH dehydrogenase (ubiquinone) Fe-S protein 1, } 75 \mathrm{kDa} \text { (NADH-coenzyme } \\
\text { Q reductase) }\end{array}$ & NDUFS1 & 1.71 & 0.0470 \\
\hline BI899164 & Transmembrane protein 64 & TMEM64 & 1.69 & 0.0475 \\
\hline CK770586 & Nidogen 2 (osteonidogen) & NID2 & 1.69 & 0.0480 \\
\hline BP102089 & Family with sequence similarity $122 \mathrm{~B}$ & FAM122B & 1.68 & 0.0355 \\
\hline CK946415 & Acyl-CoA oxidase 1, palmitoyl & ACOXI & 1.67 & 0.0226 \\
\hline CK955814 & Ectonucleotide pyrophosphatase/phosphodiesterase 2 & ENPP2 & 1.64 & 0.0154 \\
\hline BE722703 & Translocase of inner mitochondrial membrane 13 homologue (yeast) & TIMM13 & 1.64 & 0.0384 \\
\hline CK846596 & Proline-rich Gla (G-carboxyglutamic acid) 1 & PRRG1 & 1.58 & 0.0467 \\
\hline CB437963 & - & - & 1.57 & 0.0284 \\
\hline AV613409 & Adrenergic $\beta$ receptor kinase 2 & $A D R B K 2$ & 1.54 & 0.0481 \\
\hline CK947524 & - & - & 1.54 & 0.0038 \\
\hline NM_174767.2 & Visual system homeobox 1 & $V S X 1$ & 1.54 & 0.0308 \\
\hline NM_175785.2 & ATPase $\mathrm{Ca}^{2+}$ transporting, type $2 \mathrm{C}$, member 1 & $A T P 2 C 1$ & 1.53 & 0.0148 \\
\hline AW631892 & Hypothetical protein LOC100140164 & LOC100140164 & 1.52 & 0.0130 \\
\hline AU275513 & Inosine triphosphatase (nucleoside triphosphate pyrophosphatase) & ITPA & 1.52 & 0.0131 \\
\hline CK961806 & 4076044 BARC 9BOV Bos taurus cDNA clone 9BOV10_J05 3', mRNA sequence & - & 1.52 & 0.0439 \\
\hline CK964884 & ZMYM6 protein & LOC618247 & 1.52 & 0.0312 \\
\hline CB461358 & Nucleoporin 62 & LOC516074 & 1.50 & 0.0327 \\
\hline \multicolumn{5}{|c|}{ Downregulated in Holstein oocytes } \\
\hline BE757556 & - & - & -1.51 & 0.0346 \\
\hline CK848917 & Histidyl-tRNAsynthetase & HARS & -1.51 & 0.0249 \\
\hline BE483227 & 169309 BARC 5BOV Bos taurus cDNA 5', mRNA sequence & - & -1.51 & 0.0138 \\
\hline CK845823 & Homo sapiens polymerase (DNA directed), gamma & $P O L G$ & -1.52 & 0.0153 \\
\hline CK775030 & Importin 9 & IPO9 & -1.53 & 0.0237 \\
\hline CK975976 & Death-associated protein & $D A P$ & -1.53 & 0.0382 \\
\hline CB167910 & Pelota homologue (Drosophila) & PELO & -1.54 & 0.0409 \\
\hline CK976501 & Signal peptidase complex subunit 3 homologue (S. cerevisiae) & SPCS3 & -1.54 & 0.0001 \\
\hline CK776838 & Phosphodiesterase 8B & $P D E 8 B$ & -1.55 & 0.0172 \\
\hline BI535325 & 398771 MARC 4BOV Bos taurus cDNA 5', mRNA sequence & - & -1.56 & 0.0271 \\
\hline CK975798 & - & - & -1.59 & 0.0103 \\
\hline CB421951 & CD3g molecule, gamma (CD3-TCR complex) & $C D 3 G$ & -1.60 & 0.0467 \\
\hline CK773978 & 962683 MARC 2BOV Bos taurus cDNA 3', mRNA sequence & - & -1.60 & 0.0082 \\
\hline CK968887 & Family with sequence similarity 46 , member B & FAM46B & -1.62 & 0.0460 \\
\hline CK951562 & MAX dimerisation protein 1 & $M X D 1$ & -1.63 & 0.0130 \\
\hline CB468445 & 734266 MARC 6BOV Bos taurus cDNA 3', mRNA sequence & - & -1.64 & 0.0044 \\
\hline CK777507 & Peroxisomal biogenesis factor $11^{\mathrm{a}}$ & PEX11A & -1.66 & 0.0499 \\
\hline
\end{tabular}


Table 3. (Continued)

\begin{tabular}{|c|c|c|c|c|}
\hline $\begin{array}{l}\text { Representative } \\
\text { public ID }\end{array}$ & Gene name & Gene symbol & $\begin{array}{l}\text { Fold- } \\
\text { change }\end{array}$ & $P$-value \\
\hline CK772584 & SCO cytochrome oxidase deficient homologue 1 (yeast) & SCO1 & -1.68 & 0.0068 \\
\hline CK846593 & 969102 MARC 4BOV Bos taurus cDNA 3', mRNA sequence & - & -1.68 & 0.0196 \\
\hline CB437808 & Zinc finger protein 362 & ZNF362 & -1.69 & 0.0182 \\
\hline CB421497 & 594518 MARC 6BOV Bos taurus cDNA 3', mRNA sequence & - & -1.69 & 0.0051 \\
\hline CK772342 & GPCR37 (endothelin receptor type B-like) /similar to probable GPCR37 & $\begin{array}{l}\text { GPR37 } \\
\text { LOC790388 }\end{array}$ & -1.73 & 0.0024 \\
\hline CK950060 & Predicted: Bos taurus transmembrane protein 87B & TMEM87B & -1.73 & 0.0183 \\
\hline CK957150 & 4097464 BARC 10BOV Bos taurus cDNA clone 10BOV3_F15 3', mRNA sequence & - & -1.75 & 0.00006 \\
\hline CK953377 & Hypothetical LOC614796 & MGC157372 & -1.76 & 0.0215 \\
\hline CB426313 & Paraneoplastic antigen MA2 & PNMA2 & -1.77 & 0.0451 \\
\hline CB430767 & - & - & -1.78 & 0.0474 \\
\hline X61612.1 & ATPase $\mathrm{H}^{+}$transporting, lysosomal $70 \mathrm{kDa}, \mathrm{V} 1$ subunit A & ATP6V1A & -1.79 & 0.0498 \\
\hline BI848836 & Two pore segment channel 1 & TPCN1 & -1.80 & 0.0133 \\
\hline CB421732 & GPCR155 & GPR155 & -1.87 & 0.0195 \\
\hline BF073634 & $\begin{array}{l}\text { Similar to stromal membrane-associated GTPase-activating protein 2; small } \\
\text { ArfGAP2 }\end{array}$ & $\begin{array}{l}\text { LOC790140 /// } \\
\text { SMAP2 }\end{array}$ & -1.92 & 0.0317 \\
\hline CB459849 & RNA binding motif protein 25 & RBM25 & -1.92 & 0.0280 \\
\hline CB443312 & - & - & -1.95 & 0.0284 \\
\hline CB451835 & 706630 MARC 6BOV Bos taurus cDNA 3', mRNA sequence & - & -1.99 & 0.0045 \\
\hline CK952663 & - & - & -2.00 & 0.0028 \\
\hline CK951211 & - & - & -2.12 & 0.0084 \\
\hline CK774760 & Nipsnap homologue $3 \mathrm{~A}$ & NIPSNAP $3 A$ & -2.13 & 0.0013 \\
\hline AW656161 & TRANSMEMBRANE protein 167B & TMEM167B & -2.15 & 0.0133 \\
\hline CK775789 & Transmembrane protein 97 & TMEM97 & -2.22 & 0.0410 \\
\hline CK948712 & $\begin{array}{l}\text { Predicted: Bos taurus A kinase (PRKA) } \\
\text { Anchor protein } 12\end{array}$ & AKAP12 & -2.41 & 0.0085 \\
\hline BM445534 & Uncharacterised LOC100849050 & LOC100849050 & -3.03 & 0.0364 \\
\hline CB461876 & 721905 MARC 6BOV Bos taurus cDNA 3', mRNA sequence & - & -3.14 & 0.0475 \\
\hline CK770657 & 958857 MARC 1BOV Bos taurus cDNA $3^{\prime}$, mRNA sequence & - & -3.16 & 0.0268 \\
\hline CK730220 & Homo sapiens polypyrimidine tract binding protein 3 & PTBP3 & -3.27 & 0.0116 \\
\hline AW484451 & 60795 MARC 4BOV Bos taurus cDNA 5', mRNA sequence & - & -3.74 & 0.0004 \\
\hline
\end{tabular}

Table 4. Differentially expressed genes in control and heat-shocked oocytes (temperature effect) UPF3, xxx; FBR-MuSV, Finkel-Biskis-Reilly murine sarcoma virus

\begin{tabular}{|c|c|c|c|c|}
\hline $\begin{array}{l}\text { Representative } \\
\text { public ID }\end{array}$ & Gene name & Gene symbol & $\begin{array}{l}\text { Fold- } \\
\text { change }\end{array}$ & $P$-value \\
\hline \multicolumn{5}{|c|}{ Upregulated in heat-shocked oocytes } \\
\hline CK946415 & Acyl-CoA oxidase 1, palmitoyl & $A C O X 1$ & 1.88 & 0.0084 \\
\hline CK950864 & $\begin{array}{l}\text { Gag-Pro-Pol-Env protein; similar to envelope glycoprotein; similar to envelope } \\
\text { glycoprotein; tetratricopeptide repeat domain } 8\end{array}$ & $\begin{array}{l}\text { LOC782627 / } \\
\text { LOC786117 / } \\
\text { LOC787886 / } \\
\text { TTC8 }\end{array}$ & 1.62 & 0.0387 \\
\hline BE668935 & UPF3 regulator of nonsense transcripts homologue A (yeast) & $U P F 3 A$ & 1.52 & 0.0356 \\
\hline \multicolumn{5}{|c|}{ Downregulated in heat-shocked oocytes } \\
\hline BP100734 & Ribosomal protein, large, $\mathrm{P} 1$ & $R P L P 1$ & -1.51 & 0.0421 \\
\hline BE685559 & Metallothionein 1E & $M T 1 E$ & -1.52 & 0.0436 \\
\hline NM_174731.2 & FBR-MuSV ubiquitously expressed & $F A U$ & -1.61 & 0.0403 \\
\hline CK978935 & Splicing factor $3 \mathrm{~b}$, subunit $4,49 \mathrm{kDa}$ & $S F 3 B 4$ & -1.62 & 0.0203 \\
\hline CB447642 & Coronin $1 \mathrm{C}$ & CORO1C & -1.67 & 0.0457 \\
\hline CK776273 & Chromosome 11 open reading frame 16 & C11ORF16 & -1.89 & 0.0360 \\
\hline
\end{tabular}


Table 5. Differentially expressed genes affected by breed $\times$ temperature interaction in bovine oocytes TCP1, T-Complex Polypeptide 1

\begin{tabular}{|c|c|c|c|c|}
\hline Representative public ID & Gene name & Gene symbol & Fold-change & $P$-value \\
\hline CK776338 & Oncostatin M receptor & OSMR & 1.64 & 0.0303 \\
\hline CK728156 & $\begin{array}{l}\text { UMC-bend_0A02-007-a09 Day } 8 \text { Uterus bend Bos taurus cDNA 3', } \\
\text { mRNA sequence }\end{array}$ & - & 1.51 & 0.0482 \\
\hline CK946415 & Acyl-CoA oxidase 1, palmitoyl & ACOXI & -1.58 & 0.0359 \\
\hline CB451598 & Chaperonin containing TCP1, subunit 4 & CCT4 & -1.61 & 0.0259 \\
\hline CB446568 & DENN/MADD domain containing 3 & DENND3 & -1.68 & 0.0318 \\
\hline NM_203359.1 & Dicer 1, ribonuclease type III & DICER1 & -1.77 & 0.0400 \\
\hline
\end{tabular}

Table 6. Further analysis of differentially expressed genes modulated by breed $\times$ temperature interactions in bovine oocytes ACOX1, acyl-coenzyme A oxidase 1, palmitoyl; CCT4, chaperonin containing TCP1, subunit 4; DENND3, DENN/MADD domain containing 3; DICER1, dicer 1, ribonuclease type III; OSMR, oncostatin M receptor; HS, heat shock

\begin{tabular}{llcr}
\hline Gene symbol & Comparison & Fold-change & Upregulated \\
\hline CCT4 & Holstein control $\times$ Holstein HS & 1.87 & 0020 \\
ACOX1 & Holstein control $\times$ Holstein HS & 2.50 & 0005 \\
& Nelore HS $\times$ Holstein HS & 2.48 & 0007 \\
DICER1 & Nelore HS $\times$ Holstein HS & 3.81 & 0009 \\
OSMR & Nelore HS $\times$ Holstein HS & -2.32 & 0007 \\
DENND3 & Nelore control $\times$ Holstein control & -1.89 & Holstein HS \\
\end{tabular}

oocytes involved cellular compromise ( $A C O X 1$ and $M T 1 E)$, cell cycle $(M T 1 E)$, developmental disorders (splicing factor $3 \mathrm{~b}$, subunit $4(S F 3 B 4)$ and $A C O X 1)$, lipid metabolism $(A C O X 1)$, molecular transport ( $A C O X 1$ and $M T 1 E)$, energy production $(A C O X 1)$, free radical scavenging (MT1E) and cellular assembly and organisation ( $A C O X 1$ and coronin $1 \mathrm{C}$ (CORO1C); Fig. 5). The interaction of breed and temperature also indicated differently expressed $(P<0.05)$ genes involved in significant main biological processes $(P<0.05)$ such as cell cycle (DICER1), cell morphology (OSMR), cellular assembly, organisation and compromise (ACOX1 and DICER1), cellular development (OSMR and DICER1), lipid metabolism (ACOX1), post-translational modification and protein folding (CCT4) and protein catabolism (DENND3; Fig. 5). Gene terminology is described in Tables 3-5.

\section{Oocyte real-time PCR}

Real-time PCR was conducted to validate genes affected by breed (KIF3A, CLDN11, BIRC3 and DAP), temperature (MT1E) and the breed $\times$ temperature interaction (CCT4, DICERI, $D E N N D 3$ and $A C O X 1)$ in bovine oocytes. Initial analysis showed that microarray and real-time PCR fold-changes had a Pearson's correlation coefficient of $r=0.77(P=0.01$; Fig. 6). This indicated that the differential level of expression for the transcripts KIF3A, CLDN11, BIRC3, DAP, MTIE, CCT4, $D E N N D 3$ and $A C O X 1$ detected in both microarray and realtime PCR analyses were highly correlated. However, real-time PCR validation confirmed statistically significant expression of $22 \%$ of selected genes in oocytes $(2 / 9$; Figs 7,8$)$. The relative mRNA abundance for the molecular motor $K I F 3 A$ was higher $(P<0.05$; Fig. 7a) for Holstein than Nelore oocytes. In contrast, the relative abundance of $D A P(P<0.05$; Fig. $7 a)$ and DENND3 $(P<0.001$; Fig. 9) mRNA was higher in Nelore than Holstein oocytes. Even though real-time PCR data showed that DENND3 gene expression was affected by breed, this gene was not considered as validated because according to microarray data there was a breed $\times$ temperature interaction. For the other genes evaluated, there was no statistically significant difference for breed (CLDN11 and BIRC3), temperature $(M T I E)$ or the breed $\times$ temperature interaction $(C C T 4$, $D I C E R 1$ and DENND3). The $A C O X 1$ gene was not detected by real-time PCR.

\section{CC real-time PCR}

Real-time PCR was conducted to determine how genes that were differentially expressed in the oocyte microarray behaved in CCs subjected to the same treatments. Expression of CLDN11 in CCs was affected by breed: relative $C L D N 11$ mRNA abundance was higher for Nelore than Holstein CCs $(P=0.06$; Fig. 10a). $M T 1 E$ expression was affected by both breed $(P<0.05)$ and temperature $(P<0.05)$. Relative MT1E mRNA abundance was higher for Holstein than Nelore CCs $(P<0.05$; Fig. 10a) and exposure of COCs to heat shock decreased CC MTIE mRNA expression $(P<0.05$; Fig. 10b). There was no effect of breed, temperature of the breed $\times$ temperature interaction on the relative mRNA abundance of KIF3A, BIRC3,DAP, CCT4 and DICER1 in CCs (Fig. 10). ACOX1 and DENND3 mRNAs were not expressed in these CCs. 
(a) 4.0
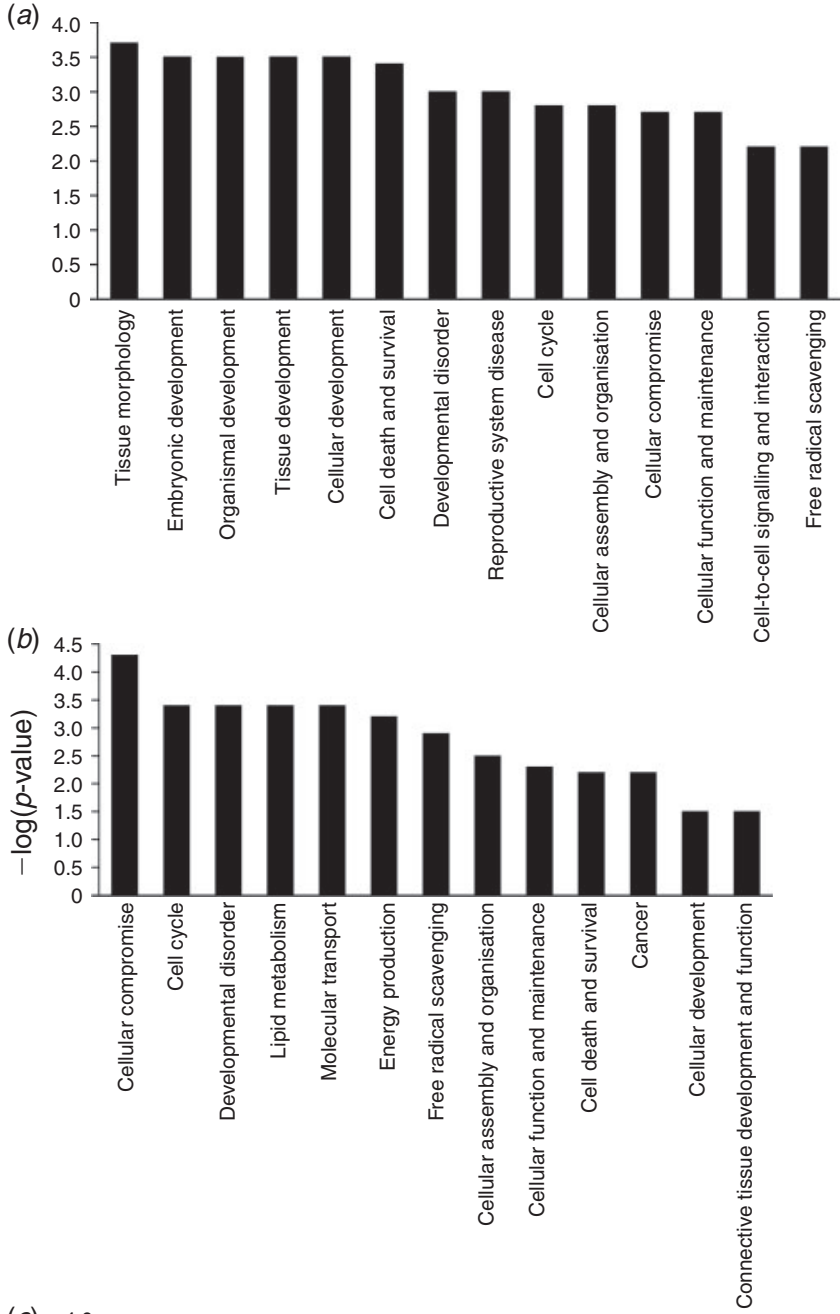

(c)

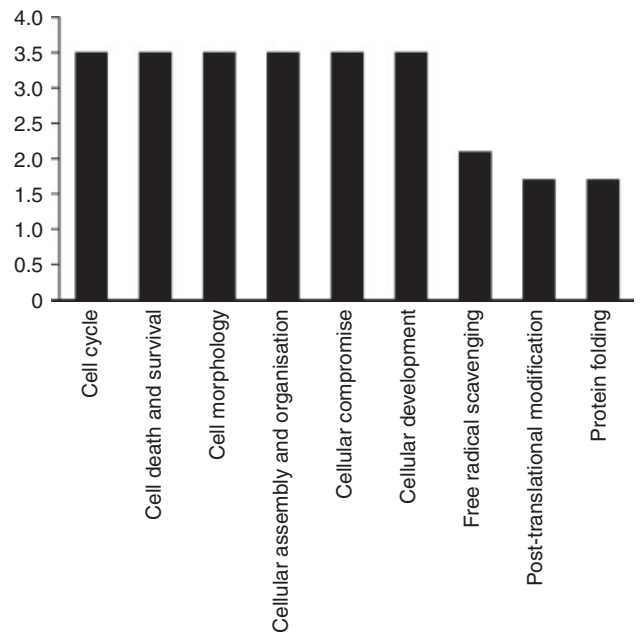

Fig. 5. Biological processes for differentially expressed genes in oocytes affected by $(a)$ breed, $(b)$ temperature and $(c)$ the breed $\times$ temperature interaction. Data were obtained using ingenuity pathway analysis software (Ingenuity Systems; www.ingenuity.com, accessed 15 February 2013).

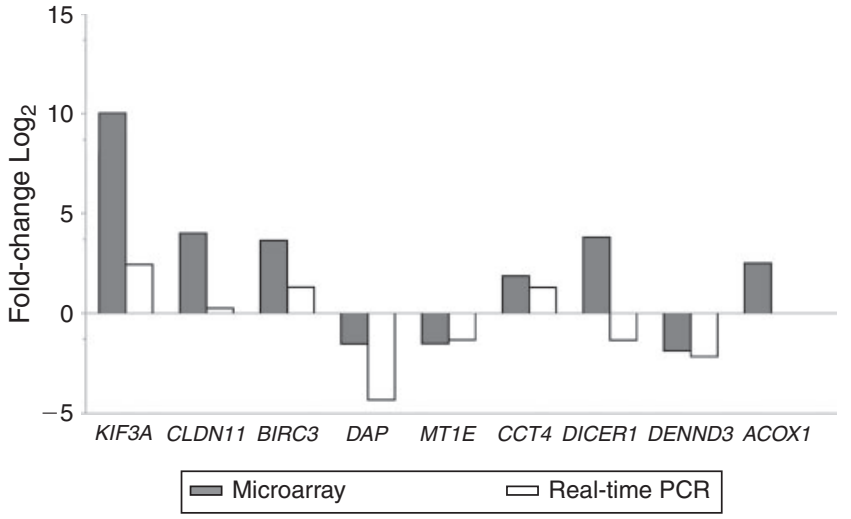

Fig. 6. Quantification (fold-change, $\log _{2}$ ) of the mRNA profile for selected genes in oocytes. Kinesin family member 3A (KIF3A), claudin 11 (CLDN11), baculoviral IAP repeat-containing 3 (BIRC3) and deathassociated protein $(D A P)$ were differentially expressed between breeds; metallothionein $1 \mathrm{E}$ (MTIE) was differentially expressed between temperature treatments (heat shock vs control); and chaperonin containing TCP1, subunit 4 (CCT4), acyl-coenzyme A oxidase 1, palmitoyl (ACOX1), dicer 1, ribonuclease type III (DICERI) and DENN/MADD domain containing 3 $(D E N N D 3)$ were affected by the breed $\times$ temperature interaction. Grey bars represent the differential level of expression of transcripts detected in the microarray study, whereas white bars represent the differential level of expression of the same transcripts obtained by real-time polymerase chain reaction (PCR; fold-change $=2^{-\Delta \Delta C T}$ ). Pearson's correlation coefficient between PCR and microarray fold change values is $r=0.7778(P=0.01)$.

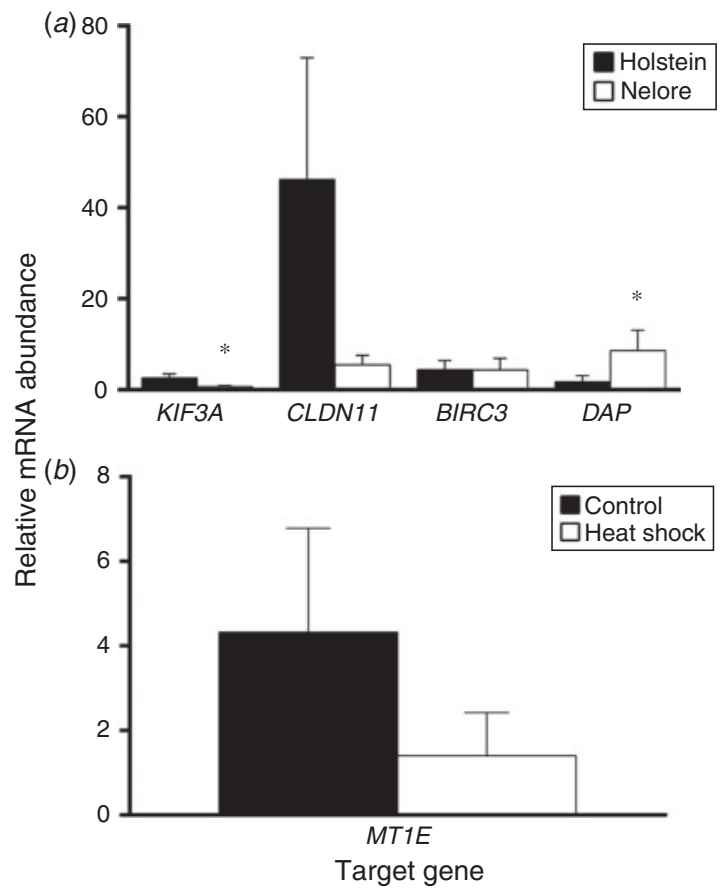

Fig. 7. Effects of (a) breed (Holstein vs Nelore) and (b) temperature (control vs heat shock) on mRNA abundance (relative to beta-actin gene $(A C T B)$ of differentially expressed genes in oocytes. Data are the leastsquares mean \pm s.e.m. of three replicates using 75 oocytes per group. $* P<0.05$ compared with Holstein animals. KIF3A, kinesin family member 3A; CLDN11, claudin 11; BIRC3, baculoviral IAP repeat-containing 3; $D A P$, death-associated protein; $M T 1 E$, metallothionein 1E. 
(a)
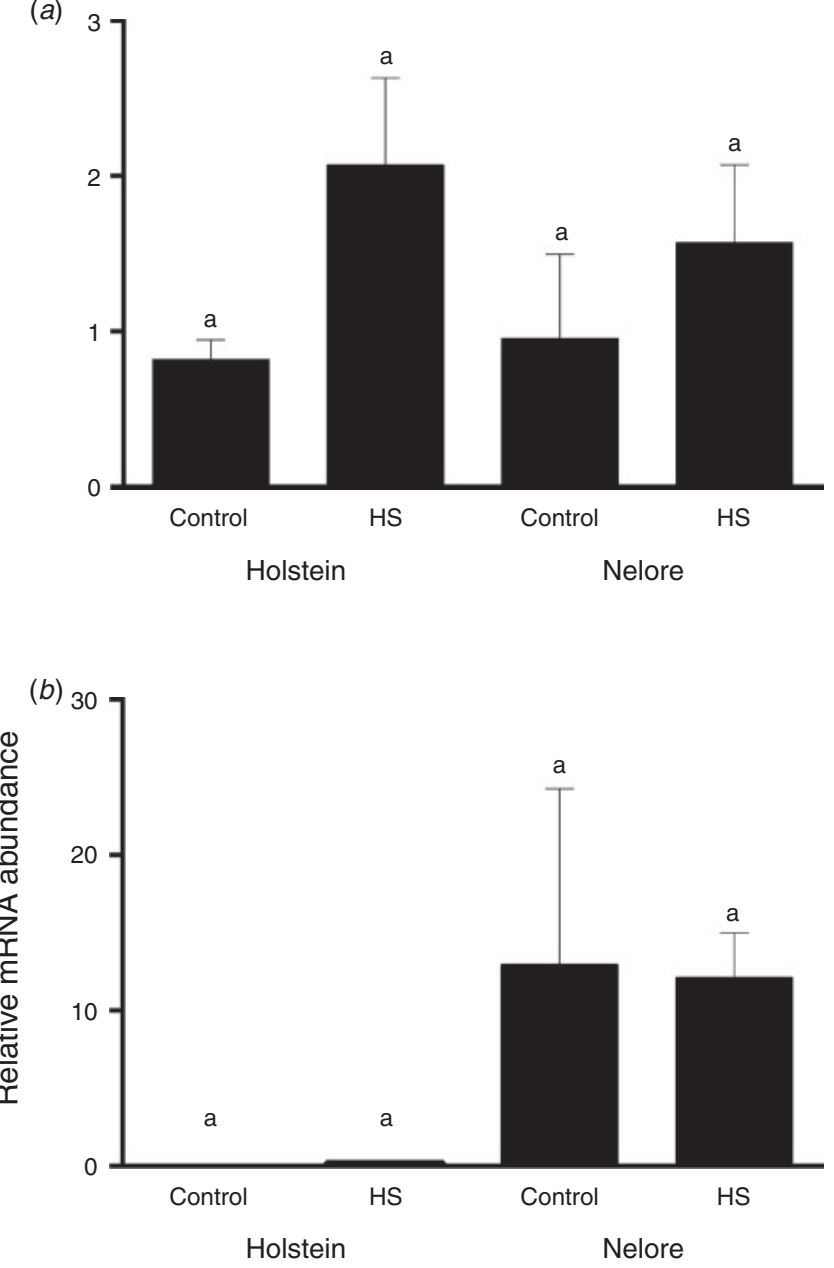

(c)

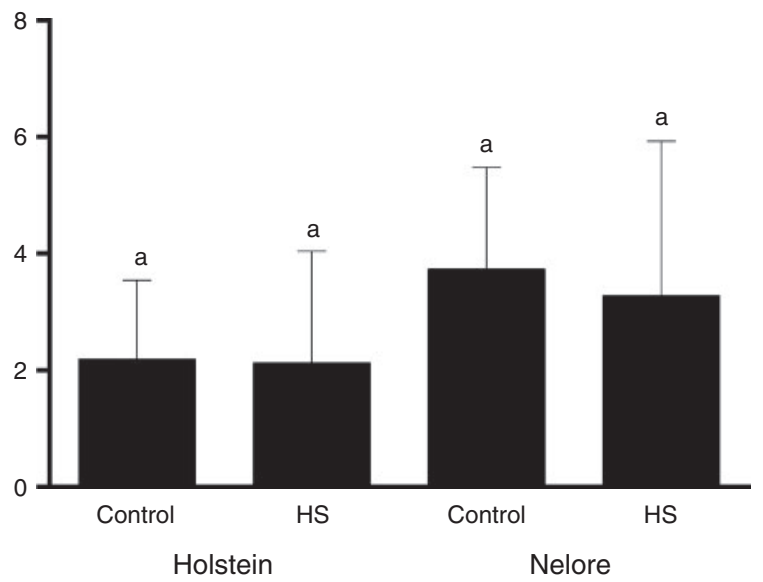

Fig. 8. Effects of the interaction of breed $\times$ temperature on mRNA abundance (relative to beta-actin gene $(A C T B)$ of three differentially expressed genes in oocytes. (a) Chaperonin containing TCP1, subunit 4 (CCT4), (b) DENN/MADD domain containing 3 (DENND3) and (c) dicer 1, ribonuclease type III (DICERI). Results are the east-squares mean \pm s.e.m. of three replicates using 75 oocytes per group. HS, heat shock.

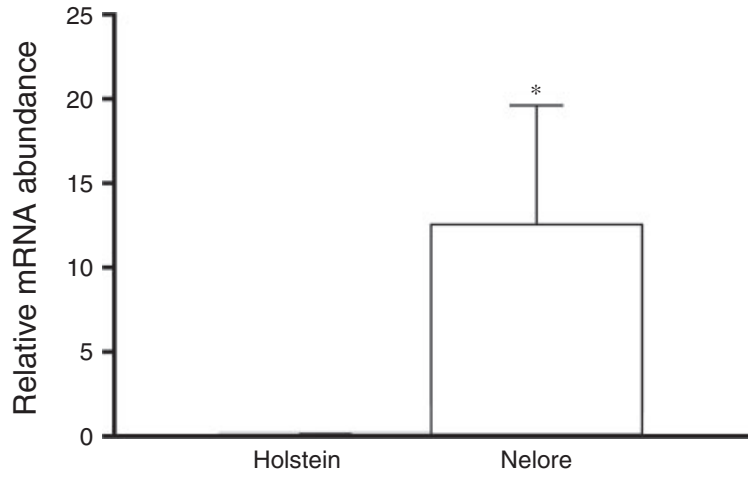

Fig. 9. Effects of breed (Holstein and Nelore) on mRNA abundance (relative to ribosomal protein L30 (RPL30)) of the DENN/MADD domain containing 3 (DENND3) gene in oocytes. Results are the least-square mean \pm s.e.m. of three replicates using 75 oocytes per group. ${ }^{*} P<0.001$ compared with Holstein animals.

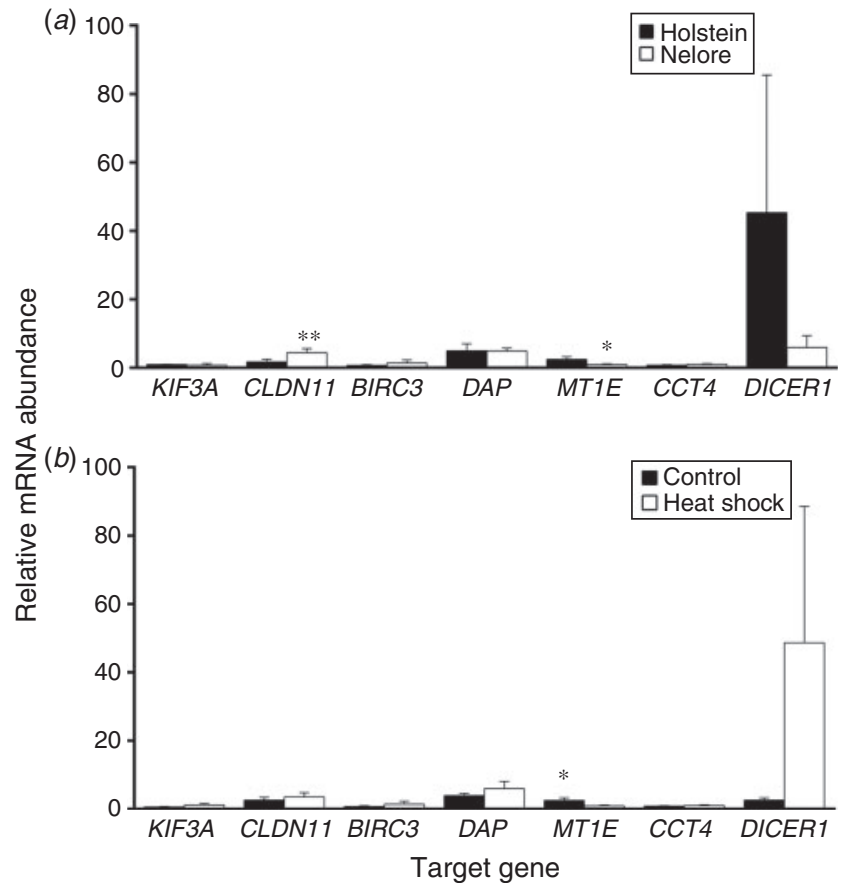

Fig. 10. Effects of (a) breed (Holstein vs Nelore) and (b) temperature (control vs heat shock) on mRNA abundance (relative to ribosomal protein L30 (RPL30)) of differentially expressed genes in cumulus cells. Results are the least-squares mean \pm s.e.m. of five replicates. ${ }^{*} P<0.05$, $* * P=0.06$ compared with Holstein animals ( $a$ ) or control treatment $(b)$. KIF3A, kinesin family member $3 \mathrm{~A} ; C L D N 11$, claudin $11 ; B I R C 3$, baculoviral IAP repeatcontaining 3; DAP, death-associated protein; MTIE, metallothionein 1E; $C C T 4$, chaperonin containing TCP1, subunit 4; DICER1, dicer 1, ribonuclease type III.

\section{Discussion}

High ET have considerable economic impact on cattle production worldwide. The present study analysed global changes in gene expression in B. taurus taurus and B. taurus indicus oocytes subjected to heat shock and the relative abundance of 
candidate genes in their CCs. The present is the first to evaluate the molecular mechanisms by which temperature and genotype affect oocyte and CCs.

Expression of the microtubule-dependent molecular motor KIF3A was higher in Holstein than Nelore oocytes. KIF3A protein has been localised to the spindle microtubules and around the cellular cortex of HeLa cells (Haraguchi et al. 2006). This member of the kinesins superfamily uses energy derived from ATP hydrolysis to promote unidirectional transport of organelles along the microtubules and completion of cytokinesis. For example, kinesins allow positioning of nuclei and proper segregation of genetic material (Shimizu et al. 1998). This implies an important role for KIF3A in the progression of meiosis in Holstein oocytes.

There is accumulating evidence that the mammalian cytoskeleton is susceptible to extremes of temperature. It has been shown that exposure of oocytes to heat shock (Roth and Hansen 2005) and cryopreservation (Wu et al. 2006) compromises cytoskeletal architecture, leading to spindle microtubule and actin filament disorganisation. In the present study, exposure of Nelore and Holstein oocytes to a physiologically relevant heat shock of $41^{\circ} \mathrm{C}$ for the first $12 \mathrm{~h}$ of IVM did not affect the expression of the microtubule-dependent molecular motor $K I F 3 A$. It is possible that such stress was not severe enough to induce changes in $K I F 3 A$ transcript abundance during oocyte maturation. Indeed, more severe stress, such as cryopreservation, has been reported to downregulate $K I F 3 A$ in human MII oocytes (Monzo et al. 2012). Even though the effects of high temperature on cytoskeletal organisation have been well characterised in bovine oocytes (Roth and Hansen 2004), little is know about the effects of high temperatures on the expression of cytoskeleton-associated transcripts.

The DAP transcript has not been previously described in bovine oocytes. In the present study, the abundance of the proapoptotic $D A P$ transcript was higher in Nelore than Holstein oocytes. Although this higher abundance of $D A P$ transcript may render the Nelore oocyte more prone to cell death, it may also make the Nelore embryo more capable of adapting to stress conditions. Apoptosis has been demonstrated to be an adaptive response in bovine preimplantation embryos that facilitates survival after heat shock (Paula-Lopes and Hansen 2002). This is supported by the finding that Brahman embryos are more resistant to elevated temperatures than Angus and Holstein embryos (Paula-Lopes et al. 2003). Moreover, as the embryo reaches the blastocyst stage, $D A P$ transcript expression did not differ between Simmental (B. taurus taurus) and Nelore (B. taurus indicus) embryos (Sudano et al. 2013).

Nelore and Holstein oocyte transcriptome analysis demonstrated that the molecular motor KIF3A and the pro-apoptotic $D A P$ genes were differentially expressed between breeds. Even though such breed difference occurred independent of temperature, these genes encode important proteins associated with cellular events highly susceptible to heat shock, such as oocyte nuclear maturation, cytoskeletal organisation (Roth and Hansen 2005) and apoptosis (Roth and Hansen 2004; Paula-Lopes et al. 2013). Interestingly, although Holstein oocytes are known to be susceptible to heat stress (Rocha et al. 1998), the KIF3A transcript, which favours meiotic division, was more abundant in Holstein than Nelore oocytes. It is possible that Holstein oocytes have a lower stress baseline so that exposure to the IVM system triggered earlier changes in transcript abundance compared with Nelore oocytes. Another possibility is that Holstein oocyte deficiency in cellular protection against heat stress occurs at the post-transcriptional or protein level rather than involving transcript regulation. Indeed, it has been demonstrated that exposure of bovine oocytes to heat shock during the first $12 \mathrm{~h}$ of IVM does not affect oocyte RNA integrity, total RNA and poly(A) RNA abundance or the abundance of specific transcripts (HSP70, growth differentiation factor 9 (GDF9), bone morphogenetic protein 15 (BMP15), poly(A) polymerase $(P A P)$, cyclin B1 $(C C N B 1), 28 S$ and $18 S)$ in bovine oocytes (Payton et al. 2011).

Another gene that was differentially expressed between Holstein and Nelore oocytes was DENND3. Even though $D E N N D 3$ encodes an evolutionarily conserved protein, little has been shown regarding its functional roles. DENN domains interact directly with members of the Rab family of small GTPases and function enzymatically as Rab-specific guanine nucleotide exchange factors (Yoshimura et al. 2010). Rab GTPases play a role in membrane trafficking, cell growth and differentiation (Schwartz et al. 2007). DENND3 acts as regulator of Rab12 function (Matsui and Fukuda 2011), which controls transferrin receptor degradation and recycling (Matsui et al. 2011). Transferrin receptor, a regulator of intracellular iron homeostasis, has been demonstrated in baboon oocytes (Burch et al. 2009). Iron accumulation catalyses hydroxyl radical formation amplifying oxidative damage (Asano 2012). Moreover, it induces transferrin receptor degradation at lysosomes, a mechanism that is required for iron homeostasis in mammalian cells (Tachiyama et al. 2011). Therefore, high DENND3 mRNA abundance suggests that Nelore oocytes are better able to control iron balance, avoiding oxidative stress and defects in nuclear events during IVM.

The positive correlation between fold-changes in oocyte microarray and real-time PCR validation indicated high similarity in the gene expression profile between these two techniques. Of the nine genes evaluated (KIF3A, CLDN11, BIRC3, DAP, MT1E, CCT4, DICER1, DENND3 and ACOX1), the expression of seven was directly proportional between microarray and real-time PCR. Despite this high correlation, a more conservative analysis indicated that only two of the nine genes were statistically significant on real-time PCR validation. Although a higher number of repetitions lead to greater uniformity between samples, potentially increasing the proportion of validated genes, the low number of validated genes must not have occurred in this study due to the number of repetitions used in real time PCR (three biological replicates). It has been shown that an experiment should ideally include at least three independent biological replicates for each treatment (Udvardi et al. 2008). In addition, three biological replicates has been used as the default number to other microarray studies reported in the literature (Grado-Ahuir et al. 2011; Dias et al. 2013).

Considering the importance of CCs in oocyte competence, the present study broadened the investigation of genes differentially expressed in oocytes to the surrounding CCs. Tight junction claudin (CLDN11) expression was higher in Nelore 
than Holstein CCs. In the bovine, several genes from the claudin family have been identified in granulosa cells of atretic follicles (CLDN1, CLDN5, CLDN11), suggesting that this protein family exerts a modulatory role on the apoptotic cascade in atretic follicles (Hatzirodos et al. 2014). Even though a modulatory action of claudins on the apoptotic cascade has not been demonstrated, there is evidence that CLDN1 had an antiapoptotic action in tumour cells (Akasaka et al. 2010).

Heat stress increases the production of reactive oxygen species (ROS) in bovine oocytes and the percentage of terminal deoxyribonucleotidyl transferase-mediated dUTP-digoxigenin nick end-labelling (TUNEL)-positive CCs (Nabenishi et al. 2012). CCs have a critical role in protecting oocytes against oxidative stress-induced apoptosis during IVM (Tatemoto et al. 2000). Endogenous antioxidant networks of CCs acts through gap junction communication to reduce ROS toxicity (Cetica et al. 2001). In the present study, exposure of bovine COCs to heat shock during IVM downregulated MTIE mRNA in CCs. Similarly, this transcript was reduced in Nelore compared with Holstein CCs. The MT1E protein exhibits antioxidant activity (Chung et al. 2006), acting as a scavenger of the free radicals hydrogen peroxide, superoxide and hydroxyl radical (Babula et al. 2012). MT1E mRNA undergoes post-transcriptional regulation (Gurel et al. 2005) so that metallothionein protein levels often do not correlate with mRNA expression (Vasconcelos et al. 2002). Therefore, heat-induced reductions in MTlE mRNA expression in CCs in the present study may have been due to increased protein synthesis for the protection of both CCs and oocytes. Similarly, reduced MTIE abundance in heatshocked oocytes suggests greater mRNA usage during heat shock.

Exposure of Holstein and Nelore COCs to $41^{\circ} \mathrm{C}$ during IVM did not affect the mRNA expression of $K I F 3 A, B I R C 3, D A P$, CCT4 and DICER 1 in CCs. This result is in agreement with the microarray study conducted by Rispoli et al. (2013), who found that the expression of these genes in CCs derived from Holstein COCs subjected to $41^{\circ} \mathrm{C}$ during IVM were not affected by temperature. There is evidence that mRNA expression of human $B I R C 3$ and $D A P$ is downregulated in CCs from polycystic ovary patients (Haouzi et al. 2012).

In conclusion, global changes in the gene expression profile of Nelore and Holstein oocytes subjected to control and heat shock treatments during IVM indicate a strong difference between breeds. Such differences were not regulated by temperature. The genes regulated by oocyte breed were mostly involved in cellular organisation and cell death. In contrast, breed and temperature acted to alter CC expression of molecules involved in cellular organisation and oxidative stress. In addition, the results of the present study suggest that the deficiency in B. taurus taurus in cellular protection against heat stress is also regulated at the post-transcriptional and protein level.

\section{Acknowledgements}

The authors thank the Brazilian Synchrotron Light Laboratory (LNLS), Maria Eugênia R. de Camargo and Dr Jörge Kobarg at Brazilian Biosciences National Laboratory (LNBio; CNPEM, Campinas, Brazil) for their support with the GeneChip equipment. The authors also appreciate the technical support provided by Antônio Guilherme Roncada Pupulim, Cíntia
Fernandes da Silva and Daniela Franco Silva. The authors thank São Paulo Research Foundation (FAPESP; \#2007/53323-0 and \#2010/04718-5), National Council for Scientific and Technological Development (CNPq; \#478558/2008-2) and Coordination for the Improvement of Higher Level or Education - Personnel (CAPES), which funded this research.

\section{References}

Akasaka, H., Sato, F., Morohashi, S., Wu, Y., Liu, Y., Kondo, J., Odagiri, H., Hakamada, K., and Kijima, H. (2010). Anti-apoptotic effect of claudin-1 in tamoxifen-treated human breast cancer MCF-7 cells. BMC Cancer 10, doi:10.1186/1471-2407-10-548

Al-Katanani, Y. M., Webb, D. W., and Hansen, P. L. (1999). Factors affecting seasonal variation in 90 day non-return rate to first service in lactating Holstein cows in a hot climate. J. Dairy Sci. 82, 2611-2616. doi:10.3168/JDS.S0022-0302(99)75516-5

Al-Katanani, Y. M., Paula-Lopes, F. F., and Hansen, P. J. (2002). Effect of season and exposure to heat stress on oocyte competence in Holstein cows. J. Dairy Sci. 85, 390-396. doi:10.3168/JDS.S0022-0302(02) 74086-1

Armstrong, D. V. (1994). Symposium: nutrition and heat stress. Heat stress interaction with shade and cooling. J. Dairy Sci. 77, 2044-2050. doi:10.3168/JDS.S0022-0302(94)77149-6

Asano, Y. (2012). Age-related accumulation of non-heme ferric and ferrous iron in mouse ovarian stroma visualized by sensitive non-heme iron histochemistry. J. Histochem. Cytochem. 60, 229-242. doi:10.1369/ 0022155411431734

Babula, P., Masarik, M., Adam, V., Eckschlager, T., Stiborova, M., Trnkova, L., Skutkova, H., Provaznik, I., Hubalek, J., and Kizek, R. (2012). Mammalian metallothioneins: properties and functions. Metallomics 4, 739-750. doi:10.1039/C2MT20081C

Berman, A., Folman, Y., Kaim, M., Mamen, M., Herz, Z., Wolfenson, D., Arieli, A., and Graber, Y. (1985). Upper critical temperatures and forced ventilation effects for high-yielding dairy cows in a subtropical environment. J. Dairy Sci. 68, 1488-1495. doi:10.3168/JDS.S0022-0302(85) 80987-5

Blazejczyk, M., Miron, M., and Nadon, R. (2007). FlexArray: a statistical data analysis software for gene expression microarrays. (Genome Quebec: Montreal.) Available at http://genomequebec.mcgill.ca/ FlexArray [verified 22 October 2012].

Brevini Gandolfi, T. A. L., and Gandolfi, F. (2001). The maternal legacy to the embryo: cytoplasmic components and their effects on early development. Theriogenology 55, 1255-1276. doi:10.1016/S0093-691X(01) 00481-2

Burch, M. G., Li, C., Albrecht, E. D., and Pepe, G. J. (2009). Developmental regulation of the expression of the transferrin receptor and Ki67 in oocytes of the baboon fetal ovary by estrogen. Endocrine 35, 177-183. doi:10.1007/S12020-008-9133-3

Camargo, L. S. A., Viana, J. H. M., Ramos, A. A., Serapião, R. V., de Sá, W. F., Ferreira, A. M., Guimarães, M. F. M., and do Vale Filho, V. R. (2007). Developmental competence and expression of the Hsp70.1 gene in oocytes obtained from Bos indicus and Bos taurus dairy cows in a tropical environment. Theriogenology 68, 626-632. doi:10.1016/ J.THERIOGENOLOGY.2007.03.029

Cetica, P. D., Pintos, L. N., Dalvit, G. C., and Beconi, M. T. (2001). Antioxidant enzyme activity and oxidative stress in bovine oocyte in vitro maturation. IUBM Life 51, 57-64. doi:10.1080/15216540119253

Chian, R. C., and Sirard, M. A. (1995). Effects of cumulus cells and folliclestimulating hormone during in vitro maturation on parthenogenetic activation of bovine oocytes. Mol. Reprod. Dev. 42, 425-431. doi:10.1002/MRD.1080420408

Chung, M. J., Hogstrand, C., and Lee, S. J. (2006). Cytotoxicity of nitric oxide is alleviated by zinc-mediated expression of antioxidant genes. Exp. Biol. Med. (Maywood) 231, 1555-1563. 
Curtis, S. E. (1981). 'Environmental Management in Animal Agriculture.' (Animal Environment Services: Iowa.)

Decker, C. J., and Parker, R. (1994). Mechanisms of mRNA degradation in eukaryotes. Trends Biochem. Sci. 19, 336-340. doi:10.1016/0968-0004 (94) $90073-6$

Dias, F. C. F., Khan, M. I. R., Sirard, M. A., Adams, G. P., and Singh, J. (2013). Differential gene expression of granulosa cells after ovarian superstimulation in beef cattle. Reproduction 146, 181-191. doi:10.1530/REP-13-0114

Ealy, A. D., Drost, M., and Hansen, P. J. (1993). Developmental changes in embryonic resistance to adverse effects of maternal heat stress in cows. J. Dairy Sci. 76, 2899-2905. doi:10.3168/JDS.S0022-0302(93)77629-8

Edwards, J. L., and Hansen, P. J. (1996). Elevated temperature increases heat shock protein 70 synthesis in bovine two-cell embryos and compromises function of maturing oocytes. Biol. Reprod. 55, 341-346. doi:10.1095 BIOLREPROD55.2.341

Gautier, L., Cope, L., Bolstad, B. M., and Irizarry, R. A. (2004). Affy analysis of Affymetrix GeneChip data at the probe level. Bioinformatics 20, 307-315. doi:10.1093/BIOINFORMATICS/BTG405

Gendelman, M., and Roth, Z. (2012). In vivo vs. in vitro models for studying the effects of elevated temperature on the GV-stage oocyte, subsequent developmental competence and gene expression. Anim. Reprod. Sci. 134, 125-134. doi:10.1016/J.ANIREPROSCI.2012.07.009

Grado-Ahuir, J. A., Aad, P. Y., and Spicer, L. J. (2011). New insights into the pathogenesis of cystic follicles in cattle: microarray analysis of gene expression in granulosa cells. J. Anim. Sci. 89, 1769-1786. doi:10.2527/ JAS.2010-3463

Gurel, V., Sens, D. A., Somji, S., Garrett, S. H., Weiland, T., and Sens, M. A. (2005). Post-transcriptional regulation of metallothionein isoform 1 and 2 expression in the human breast and the MCF-10A cell line. Toxicol. Sci. 85, 906-915. doi:10.1093/TOXSCI/KFI155

Haghighat, N., and Van Winkle, L. J. (1990). Developmental change in follicular cell enhanced amino acid uptake into mouse oocytes that depends on intact gap junctions and transport system Gly. J. Exp. Zool. 253, 71-82. doi:10.1002/JEZ.1402530110

Hansen, P. J. (2004). Physiological and cellular adaptations of Zebu cattle to thermal stress. Anim. Reprod. Sci. 82-83, 349-360. doi:10.1016/J.ANIR EPROSCI.2004.04.011

Haouzi, D., Assou, S., Monzo, C., Vincens, C., Dechaud, H., and Hamamah, S. (2012). Altered gene expression profile in cumulus cells of mature MII oocytes from patients with polycystic ovary syndrome. Hum. Reprod. 27, 3523-3530. doi:10.1093/HUMREP/DES325

Haraguchi, K., Hayashi, T., Jimbo, T., Yamamoto, T., and Akiyama, T. (2006). Role of the kinesin-2 family protein, KIF3, during mitosis. J. Biol. Chem. 281, 4094-4099. doi:10.1074/JBC.M507028200

Hatzirodos, N., Hummitzsch, K., Irving-Rodgers, H. F., Harland, M. L., Morris, S. E., and Rodgers, R. J. (2014). Transcriptome profiling of granulosa cells from bovine ovarian follicles during atresia. BMC Genomics 15, 40. doi:10.1186/1471-2164-15-40

Kelly, C. F., and Bond, T. E. (1971). Bioclimatic factors and their measurements. In 'National Academy of Sciences, A guide to environmental research on animals'. pp. 71-92. (National Academy of Sciences: Washington.)

Leibfried, L., and First, N. L. (1979). Characterization of bovine follicular oocytes and their ability to mature in vitro. J. Anim. Sci. 48, 76-86. doi:10.2527/JAS1979.48176X

Malayer, J. R., Hansen, P. J., and Buhi, W. C. (1988). Effect of day of the oestrous cycle, side of the reproductive tract and heat shock on in vitro protein secretion by bovine endometrium. J. Reprod. Fertil. 84, 567-578. doi:10.1530/JRF.0.0840567

Matsui, T., and Fukuda, M. (2011). Small GTPase Rab12 regulates transferrin receptor degradation. Cell. Logist. 1, 155-158. doi:10.4161/CL.1.4. 18152
Matsui, T., Itoh, T., and Fukuda, M. (2011). Small GTPase Rab12 regulates constitutive degradation of transferrin receptor. Traffic 12, 1432-1443. doi:10.1111/J.1600-0854.2011.01240.X

Maya-Soriano, M. J., López-Gatius, F., Andreu-Vázquez, C., and LópezBéjar, M. (2013). Bovine oocytes show a higher tolerance to heat shock in the warm compared with the cold season of the year. Theriogenology 79, 299-305. doi:10.1016/J.THERIOGENOLOGY.2012.08.020

Monzo, C., Haouzi, D., Roman, K., Assou, S., Dechaud, H., and Hamamah, S. (2012). Slow freezing and vitrification differentially modify the gene expression profile of human metaphase II oocytes. Hum. Reprod. 27 2160-2168. doi:10.1093/HUMREP/DES153

Nabenishi, H., Takagi, S., Kamata, H., Nishimoto, T., Morita, T., Ashizawa, K., and Tsuzuki, Y. (2012). The role of mitochondrial transition pores on bovine oocyte competence after heat stress, as determined by effects of cyclosporine A. Mol. Reprod. Dev. 79, 31-40. doi:10.1002/MRD. 21401

Paula-Lopes, F. F., and Hansen, P. J. (2002). Apoptosis is an adaptive response in bovine preimplantation embryos that facilitates survival after heat shock. Biochem. Biophys. Res. Commun. 295, 37-42. doi:10.1016/S0006-291X(02)00619-8

Paula-Lopes, F. F., Chase, C. C., Jr, Al-Katanani, Y. M., Krininger, C. E., Rivera, R. M., Tekin, S., Majewski, A. C., Ocon, O. M., Olson, T. A., and Hansen, P. J. (2003). Genetic divergence in cellular resistance to heat shock in cattle: differences between breeds developed in temperate versus hot climates in responses of preimplantation embryos, reproductive tract tissues and lymphocytes to increased culture temperatures. Reproduction 125, 285-294. doi:10.1530/REP.0.1250285

Paula-Lopes, F. F., Lima, R. S., Satrapa, R. A., and Barros, C. M. (2013) Physiology and endocrinology symposium: influence of cattle genotype (Bos indicus vs. Bos taurus) on oocyte and preimplantation embryo resistance to increased temperature. J. Anim. Sci. 91, 1143-1153. doi: 10.2527/JAS.2012-5802

Payton, R. R., Rispoli, L. A., Saxton, A. M., and Edwards, J. L. (2011). Impact of heat stress exposure during meiotic maturation on oocyte, surrounding cumulus cell, and embryo RNA populations. J. Reprod. Dev. 57, 481-491. doi:10.1262/JRD.10-163M

Pfaffl, M. W. (2001). A new mathematical model for relative quantification in real-time RT-PCR. Nucleic Acids Res. 29, e45. doi:10.1093/NAR/29. 9.E45

Ramakers, C., Ruijter, J. M., Deprez, R. H. L., and Moorman, A. F. M. (2003). Assumption-free analysis of quantitative real-time polymerase chain reaction (PCR) data. Neurosci. Lett. 339, 62-66. doi:10.1016/ S0304-3940(02)01423-4

Rhoads, M. L., Rhoads, R. P., VanBaale, M. J., Collier, R. J., Sanders, S. R., Weber, W. J., Crooker, B. A., and Baumgard, L. H. (2009). Effects of heat stress and plane of nutrition on lactating Holstein cows: I. production, metabolism, and aspects of circulating somatropin. J. Dairy Sci. 92 , 1986-1997. doi:10.3168/JDS.2008-1641

Rispoli, L. A., Payton, R. R., Gondro, C., Saxton, A. M., Nagle, K. A., Jenkins, B. W., Schrick, F. N., and Edwards, J. L. (2013). Heat stress effects on the cumulus cell surrounding the bovine oocyte during maturation: altered matrix metallopeptidase 9 and progesterone production. Reproduction 146, 193-207. doi:10.1530/REP-12-0487

Rocha, A., Randel, R. D., Broussard, J. R., Lim, J. M., Blair, R. M., Roussel, J. D., Godke, R. A., and Hansel, W. (1998). High environmenta temperature and humidity decrease oocyte quality in Bos taurus but not in Bos indicus cows. Theriogenology 49, 657-665. doi:10.1016/ S0093-691X(98)00016-8

Roman-Ponce, H., Thatcher, W. W., Canton, D., Barron, D. H., and Wolcox, C. J. (1978). Thermal stress effects on uterine blood flow in dairy cows. J. Anim. Sci. 46, 175-180. doi:10.2527/JAS1978.461175X

Roth, Z., and Hansen, P. J. (2004). Involvement of apoptosis in disruption of developmental competence of bovine oocytes by heat shock during 
maturation. Biol. Reprod. 71, 1898-1906. doi:10.1095/BIOLREPROD. 104.031690

Roth, Z., and Hansen, P. J. (2005). Disruption of nuclear maturation and rearrangement of cytoskeletal elements in bovine oocytes exposed to heat shock during maturation. Reproduction 129, 235-244. doi:10.1530/ REP.1.00394

Roth, Z., Meidan, R., Braw-tal, R., and Wolfenson, D. (2000). Immediate and delayed effects of heat stress on follicular development and its association with plasma FSH and inhibin concentration in cows. J. Reprod. Fertil. 120, 83-90.

Sartori, R., Haughian, J. M., Shaver, R. D., Rosa, G. J., and Wiltbank, M. C. (2004). Comparison of ovarian function and circulating steroids in estrous cycles of Holstein heifers and lactating cows. J. Dairy Sci. 87, 905-920. doi:10.3168/JDS.S0022-0302(04)73235-X

Schwartz, S. L., Cao, C., Pylypenco, O., Rak, A., and Wandinger-Ness, A. (2007). RabGTPases at a glance. J. Cell Sci. 120, 3905-3910. doi:10.1242/JCS.015909

Shimizu, K., Shirataki, H., Honda, T., Minami, S., and Takai, Y. (1998). Complex formation of SMAP/KAP3, a KIF3A/B ATPase motorassociated protein, with a human chromosome-associated polypeptide. J. Biol. Chem. 273, 6591-6594

Silva, C. F., Sartorelli, E. S., Castilho, A. C. S., Satrapa, R. A., Puelker, R. Z., Razza, E. M., Ticianelli, J. S., Eduardo, H. P., Loureiro, B., and Barros, C. M. (2013). Effects of heat stress on development, quality and survival of Bos indicus and Bos taurus embryos produced in vitro. Theriogenology 79, 351-357. doi:10.1016/J.THERIOGENOLOGY. 2012.10.003

Smyth, G. (2005). Limma: linear models for microarray data. In 'Bioinformatics and Computational Biology Solutions Using R and Bioconductor. (Eds V. C. R. Gentleman, S. Dudoit, R. Irizarry and W. Huber.) pp. 397-420. (Springer: New York.)

Sudano, M. J., Caixeta, E. S., Paschoal, D. M., Martins, A., Machado, R., Buratini, J., and Landim-Alvarenga, F. D. (2013). Cryotolerance and global gene-expression patterns of Bos taurus indicus and Bos taurus taurus in vitro- and in vivo-produced blastocysts. Reprod. Fertil. Dev. 26, 112-114. doi:10.1071/RDV25N1AB80
Tachiyama, R., Ishikawal, D., Matsumoto, M., Nakayama, K. I., Yoshimori, T., Yokota, S., Himeno, M., Tanaka, Y., and Fujita, H. (2011). Proteome of ubiquitin QMVB pathway: possible involvement of iron-induced ubiquitylation of transferrin receptor in lysosomal degradation. Genes Cells 16, 448-466. doi:10.1111/J.1365-2443. 2011.01499.X

Tanghe, S., Van Soom, A., Nauwynck, H., Coryn, M., and de Kruif, A. (2002). Minireview: functions of the cumulus oophorus during oocyte maturation, ovulation and fertilization. Mol. Reprod. Dev. 61, 414-424. doi:10.1002/MRD.10102

Tatemoto, H., Sakurai, N., and Muto, N. (2000). Protection of porcine oocytes against apoptotic cell death caused by oxidative stress during in vitro maturation: role of cumulus cells. Biol. Reprod. 63, 805-810. doi:10.1095/BIOLREPROD63.3.805

Trounson, A., Anderiesz, C., and Jones, G. (2001). Maturation of human oocytes in vitro and their developmental competence. Reproduction 121, 51-75. doi:10.1530/REP.0.1210051

Udvardi, M. K., Czechowski, T., and Scheible, W. R. (2008). Eleven golden rules of quantitative RT-PCR. Plant Cell 20, 1736-1737. doi:10.1105/ TPC. 108.061143

Vasconcelos, M. H., Tam, S. C., Hesketh, J. E., Reid, M., and Beattie, J. H. (2002). Metal- and tissue-dependent relationship between metallothionein mRNA and protein. Toxicol. Appl. Pharmacol. 182, 91-97. doi:10.1006/TAAP.2002.9428

Wolfenson, D., Thatcher, W. W., Badinga, L., Savio, J. D., Meidan, R., Lew, B. J., Braw-Tal, R., and Berman, A. (1995). Effect of heat stress on follicular development during the estrous cycle in lactating dairy cattle. Biol. Reprod. 52, 1106-1113. doi:10.1095/BIOLREPROD52.5.1106

Wu, C., Rui, R., Dai, J., Zhang, C., Ju, S., Xie, B., Lu, X., and Zheng, X. (2006). Effects of cryopreservation on the developmental competence, ultrastructure and cytoskeletal structure of porcine oocytes. Mol. Reprod. Dev. 73, 1454-1462. doi:10.1002/MRD.20579

Yoshimura, S., Gerondopoulos, A., Linford, A., Rigden, D. J., and Barr, F. A. (2010). Family-wide characterization of the DENN domain Rab GDP-GTP exchange factors. J. Cell Biol. 191, 367-381. doi:10.1083/JCB.201008051 